\title{
In vitro responses of bone-forming MC3T3-E1 pre-osteoblasts to biodegradable Mg-based bulk metallic glasses
}

\author{
Haifei $\mathrm{Li}^{\mathrm{a}}{ }^{\mathrm{a}}$, Wei He ${ }^{\mathrm{b}, \mathrm{c}, *}$, Shujie Pang ${ }^{\text {a }}$, Peter K. Liaw ${ }^{\mathrm{b}}$, Tao Zhang ${ }^{\mathrm{a}, *}$ \\ ${ }^{a}$ Key Laboratory of Aerospace Materials and Performance (Ministry of Education), School of Materials \\ Science and Engineering, Beihang University, Beijing 100191, China \\ ${ }^{\mathrm{b}}$ Department of Materials Science and Engineering, The University of Tennessee, Knoxville, TN 37996-2100, \\ USA \\ ${ }^{c}$ Department of Mechanical, Aerospace, and Biomedical Engineering, The University of Tennessee, Knoxville, \\ TN 37996-2200, USA
}

\begin{abstract}
:
In light of the superior property profile of favorable biocompatibility, proper
\end{abstract} corrosion/degradation behavior and good mechanical properties, Mg-based bulk metallic glasses (BMGs) are considered as potential biodegradable biomaterials. In the present study, in vitro responses of bone-forming MC3T3-E1 pre-osteoblasts to Mg-Zn-Ca-Sr BMGs were studied in order to assess their feasibility to serve as orthopedic implants. The $\mathrm{Mg}-\mathrm{Zn}-\mathrm{Ca}-\mathrm{Sr} \mathrm{BMGs}$ were much more capable of supporting cell adhesion and spreading in comparison with crystalline AZ31B Mg alloy. The Mg-Zn-Ca-Sr BMG extracts showed no cytotoxicity to and slightly stimulated the proliferation of pre-osteoblasts. The cells cultured in 100\% BMG extracts exhibited lower alkaline phosphatase activity as compared with that in negative control, which could be mainly ascribed to the inhibition of high concentrations of $\mathrm{Zn}$ ions on cell differentiation. With decreasing the extract concentration, the inhibitory effect was diminished and the 5\% BMG extract exhibited slight stimulation in cell differentiation and mineralization. The high corrosion resistance of BMGs contributed to smaller environmental variations, compared with AZ31B alloy, thus lowering the unfavorable influences on cellular responses. A 
comparison among the biodegradable $\mathrm{Mg}-$, $\mathrm{Ca}-$ and $\mathrm{Sr}-$ based BMGs for their biomedical applications is presented.

Keywords: Magnesium alloy; Bulk metallic glass; Biodegradable; Corrosion; Cellular behavior; Biocompatibility

* Corresponding authors.

Dr. Wei He

Mailing Address: 303 Ferris Hall, Department of Materials Science and Engineering, University of Tennessee, Knoxville, TN 37996-2100, USA. Tel.: +1 865974 5275; Fax: +1 8659744115 E-mail address: whe5@utk.edu

Dr. Tao Zhang

Mailing Address: School of Materials Science and Engineering, Beihang University, Beijing 100191, China. Tel./fax: +861082339705.

E-mail address: zhangtao@buaa.edu.cn 


\section{Introduction}

Despite of the existing post-surgical complications, bio-inert materials including Ti alloys, stainless steels and Co-Cr alloys, which are clinically commonly-used metallic biomaterials, show extensive applications in cardiovascular stents and orthopedic implants [1-3]. The primary side effects consist of (i) the release of toxic constituent elements (i.e. $\mathrm{Al}, \mathrm{Ni}, \mathrm{Cr}$, etc.) by corrosion and friction, yielding tissue inflammatory responses, thrombosis and restenosis, which are serious issues for the applications of cardiovascular stents [1-3]; (ii) stress-shielding effects attributed to the mismatch of Young's modulus between implants and bones, which induce bone resorption and osteoporosis [4].

$\mathrm{Mg}$ alloys have garnered great attention as promising biodegradable biomaterials in recent decades, owing to their favorable biocompatibility, high mechanical strength, low Young's modulus and intriguing biodegradability [5-8]. $\mathrm{Mg}$ alloys exhibit advantages as short-term implants including bone screws, bone plates, intramedullary nails and temporary vascular stents, since the biodegradability eliminates the need of the implant-removal surgery that is costly and painful for patients. Compared with the bio-inert materials, $\mathrm{Mg}$ alloys possess much lower and more compatible Young's modulus to bones, which will help weaken the stress-shielding effects. Additionally, on account of the biocompatibility of $\mathrm{Mg}$ alloys and their degradation products, the inflammatory reactions could be mitigated and the occurrence of thrombosis and restenosis could be suppressed. Meanwhile, when used in load-bearing situations, the high strength is the superiority for Mg alloys in comparison with bioactive glasses and polymers $[9,10]$.

However, one major problem for the clinical applications of $\mathrm{Mg}$ alloys is their unsatisfactory corrosion/degradation behavior $[5,6]$. The rapid degradation rates result in not only hydrogen-gas accumulation around the implant, which retards healing process and yield tissue 
necrosis, but also fast strength reduction that goes against the proper function of implants and may cause premature failure before the healing $[8,11]$. Besides, in view of the continuous deterioration of the strength during degradation, a high intrinsic strength is preferable. Thus, improvements on the corrosion/degradation behavior and mechanical strength of $\mathrm{Mg}$ alloys are considerably merited.

One effective approach for improving the corrosion resistance of $\mathrm{Mg}$ alloys is surface coating, such as calcium deficient hydroxyapatite coating [12], CaP/chitosan/carbon nanotubes coating [13], fluoride coating [14] and polycaprolactone fibrous coating [15], which works as a corrosion-resistant barrier for the inside alloy substrate. Another approach is the amorphization of $\mathrm{Mg}$ alloys, i.e., Mg-based metallic glasses (MGs). Emerging as neoteric metallic materials characterized by amorphous structure, Mg-based bulk metallic glasses (BMGs) exhibit much higher mechanical strength, relatively low Young's modulus and enhanced corrosion resistance in contrast to conventional crystalline $\mathrm{Mg}$ alloys, indicating their potential for biomedical applications $[16,17]$. As an alloy system consisting of non-toxic elements, Mg-Zn-Ca BMGs were investigated for their bio-application prospects [17-19]. Zberg et al. [17] reported the significantly suppressed hydrogen evolution for $\mathrm{Mg}_{60+\mathrm{x}} \mathrm{Zn}_{35-\mathrm{x}} \mathrm{Ca}_{5}$ metallic glasses (MGs) with the $\mathrm{Zn}$ content higher than 28 at.\%, due to the formation of a passivating $\mathrm{ZnO} / \mathrm{ZnCO}_{3}$ layer. The in vivo tests indicated the good biocompatibility of Mg-Zn-Ca MGs and the absence of hydrogen gas cavity around the implant [17]. Gu et al. [18] illustrated the uniform corrosion of $\mathrm{Mg}-\mathrm{Zn}-\mathrm{Ca}$ BMGs and the better cytocompatibility of the BMGs in comparison with pure Mg. Chan et al. [19] prepared a gelatin coating on $\mathrm{Mg}_{67} \mathrm{Zn}_{28} \mathrm{Ca}_{5} \mathrm{MG}$, which significantly improved the cell adhesion on the alloys.

Recently, Li et al. [20] reported the development of Mg-Zn-Ca-Sr BMGs that exhibited 
larger glass-forming ability, improved mechanical strength and enhanced corrosion resistance in phosphate-buffered saline (PBS) solution as compared with Mg-Zn-Ca BMG. Additionally, Mg-Zn-Ca-Sr BMG exhibited superior corrosion-fatigue strength to crystalline Mg alloys, due to the high intrinsic strength and corrosion resistance [21]. However, detailed characterization on biocompatibility is required to fulfill a thorough assessment on the feasibility of $\mathrm{Mg}-\mathrm{Zn}-\mathrm{Ca}-\mathrm{Sr}$ BMGs to serve as orthopedic biomaterials. Commercial AZ31B Mg alloy would be employed as the crystalline reference material, since it has been extensively studied as a potential biodegradable biomaterial $[12,14,15]$. Also, despite of the important role of the differentiation and mineralization of pre-osteoblasts in the process of new bone formation, there was no report on the differentiation and mineralization behavior of pre-osteoblasts when co-cultured with Mg-based BMGs. Thus, in the present study, the in vitro responses of bone-forming MC3T3-E1 pre-osteoblasts to $\mathrm{Mg}-\mathrm{Zn}-\mathrm{Ca}-\mathrm{Sr} \mathrm{BMGs}$ and AZ31B alloy were studied, and the objectives were to: (1) investigate the biocompatibility of $\mathrm{Mg}-\mathrm{Zn}-\mathrm{Ca}-\mathrm{Sr} \mathrm{BMGs}$, especially the effect on cell differentiation and mineralization posed by these Mg-based BMGs; (2) verify the effect of corrosion resistance on biocompatibility by comparing the cellular responses to $\mathrm{Mg}-\mathrm{Zn}-\mathrm{Ca}-\mathrm{Sr}$ BMGs and AZ31B alloy.

\section{Materials and methods}

\subsection{Materials preparation}

Alloy ingots with nominal compositions of $\mathrm{Mg}_{66} \mathrm{Zn}_{30} \mathrm{Ca}_{4-\mathrm{x}} \mathrm{Sr}_{\mathrm{x}}(\mathrm{x}=0,1$ and 1.5 at.\%), which are denoted as $\mathrm{Sr} 0, \mathrm{Sr} 1$ and $\mathrm{Sr} 1.5$ in the following text, respectively, were prepared by induction-melting the mixtures of high purity $\mathrm{Mg}$ (99.9 wt.\%), Zn (99.99 wt.\%), Ca (99.9 wt.\%) and Sr (99 wt.\%) metals under an argon atmosphere. The critical diameters for glass formation of Sr0, Sr1 and Sr1.5 BMGs were $4 \mathrm{~mm}, 6 \mathrm{~mm}$ and $4 \mathrm{~mm}$, respectively [20]. From the alloy ingots, 
cylindrical rods with a diameter of $4 \mathrm{~mm}$ were fabricated by copper-mold casting under an argon atmosphere. The amorphous structure of the rods was verified by the X-ray diffraction patterns that showed only broad peaks (Fig. S1 in Supplementary material). The cylindrical rods were further cut into 1.5-mm-thick discs for cellular-behavior studies. The end surfaces of the discs were polished with $\mathrm{SiC}$ sandpaper up to 1200 grit, and afterwards, ultrasonically cleaned in acetone, ethanol and deionized water, respectively. Commercial AZ31B (3.0 wt.\% Al, 1.0 wt.\% $\mathrm{Zn}, 0.2$ wt.\% $\mathrm{Mn}$ and $\mathrm{Mg}$ as balance) $\mathrm{Mg}$ alloy samples with the same geometry were polished and cleaned as abovementioned. Prior to cellular-behavior studies, both end surfaces of the disc samples were sterilized by ultraviolet light for 30 min each.

\subsection{Surface characterization}

\subsubsection{Surface roughness}

Surface roughness of the samples was measured using a TCS SP2 laser scanning confocal microscope (Leica, Germany). Samples were scanned at 315x magnification, and the total scan area was $47.61 \mu \mathrm{m} \times 47.61 \mu \mathrm{m}$. A laser-beam wavelength of $488 \mathrm{~nm}$ and a detection pinhole of 1.00 Airy unit were used. For each alloy, four measurements on randomly-chosen areas were carried out. After taking the series scan images, the roughness values were calculated using the SurfCharJ_1q plugin of ImageJ software (NIH, USA) [22]. A LEO 1525 scanning electron microscope (SEM, LEO Electron Microscopy Ltd, Germany) was used to examine the surface morphology of the samples.

\subsubsection{Surface wettability}

Surface wettability of the samples was measured by the sessile-drop contact angle method using a CAM-Plus contact angle goniometer (Cheminstruments, USA). Both polar (deionized water, DI water) and non-polar (diiodomethane, DII) liquids were tested on the samples. For 
each alloy, five samples were tested repetitively. The surface free energy (SFE) of the specimens was calculated according to the following Owens-Wendt's equation [23]:

$$
1+\cos \theta=2\left(\gamma_{s}^{d}\right)^{1 / 2}\left[\left(\gamma_{1}^{d}\right)^{1 / 2} / \gamma_{1}\right]+2\left(\gamma_{s}^{p}\right)^{1 / 2}\left[\left(\gamma_{1}^{p}\right)^{1 / 2} / \gamma_{1}\right]
$$

where $\theta$ is the contact angle, $\gamma_{\mathrm{s}}$ is the SFE of the tested sample, $\gamma_{1}$ is the SFE of the used liquid, and the superscripts $d$ and $p$ denote the dispersive and polar components of SFE, respectively. Then, the SFE of each sample can be calculated by:

$$
\gamma_{s}=\gamma_{s}^{d}+\gamma_{s}^{p}
$$

\subsection{Cell culture and cellular behaviors}

\subsubsection{Cell culture}

Murine MC3T3-E1 pre-osteoblasts (ATCC, USA) were cultured in an alpha minimum essential medium ( $\alpha$-MEM, Invitrogen, USA) supplemented with $10 \%$ fetal bovine serum (FBS, Invitrogen, USA) and $1 \%$ antibiotics (Lifeline Cell Technology, USA) at $37{ }^{\circ} \mathrm{C}$ in a $5 \% \mathrm{CO}_{2}$ balanced air incubator. Culture medium was replaced every 2 days. Confluent cells were trypsinized and resuspended in fresh culture medium for passaging or cellular-behavior studies.

\subsubsection{Cell adhesion and morphology}

$300 \mu \mathrm{l}$ of cell suspension was seeded at a density of $5 \times 10^{3}$ cells $/ \mathrm{cm}^{2}$ on triplicate samples in a 48-well plate. After 4-h incubation, cells were rinsed with PBS, and then fixed and dehydrated following the process reported in ref. [24]. Cell morphology was observed using SEM. Images of four randomly-chosen areas on each sample were used for the cell number quantification.

\subsubsection{Sample extracts preparation}

Sample extracts were prepared by soaking samples in serum-free $\alpha$-MEM with an extraction medium volume to surface area ratio of $1.25 \mathrm{ml} / \mathrm{cm}^{2}$ at $37{ }^{\circ} \mathrm{C}$ for $72 \mathrm{~h}$, according to ISO 10993-12 [25]. The supernatant was withdrawn and centrifuged, followed by adding 10\% FBS 
and $1 \%$ antibiotics, then stored at $4{ }^{\circ} \mathrm{C}$ before tests. The $\mathrm{pH}$ and ion concentrations of the extracts were measured by a pH meter (Orion Research, USA) and an inductively coupled plasma optical emission spectrometry (ICP-OES, Thermal Fisher Scientific, USA), respectively. The control groups involved the use of $\alpha$-MEM culture medium as negative control, and $10 \%$ dimethylsulfoxide (DMSO) in $\alpha$-MEM culture medium as positive control.

\subsubsection{Cell viability}

Cell viability was studied by a live/dead staining assay. Cells were cultured in a 96-well

plate at a density of $1 \times 10^{4}$ cells $/ \mathrm{cm}^{2}$ for $24 \mathrm{~h}$, and then the $100 \mu \mathrm{l}$ of culture medium in each well was replaced with $100 \mu \mathrm{l}$ of sample extracts. After 24-h incubation, cells were rinsed with PBS and incubated in the PBS containing $2 \mu \mathrm{M}$ calcein AM and $4 \mu \mathrm{M}$ ethidium homodimer 1 (EthD-1, Thermo Fisher Scientific, USA) for $15 \mathrm{~min}$ in the incubator. Viable cells were stained with calcein AM (green), and non-viable cells were stained with EthD-1 (red). Following a PBS rinse, labeled cells were visualized by a Zeiss Axio Observer A1 inverted fluorescent microscope (Zeiss, Germany).

\subsubsection{Cell proliferation}

A water-soluble tetrazolium salt (WST-1, Roche applied science, USA) assay was used to study cell proliferation in the sample extracts. Cells were cultured in $100 \mu \mathrm{l}$ of culture medium in a 96-well plate at a density of $5 \times 10^{3}$ cells $/ \mathrm{cm}^{2}$. After $24-\mathrm{h}$ incubation, the culture medium was replaced with $100 \mu \mathrm{l}$ of sample extracts, and cells were further cultured for 1, 3 and 5 days. At each time point, cells were observed under the microscope. Subsequently, $10 \mu \mathrm{l}$ of WST-1 reagent was added to each well and incubated for $2 \mathrm{~h}$ in the incubator. Following a mixing on a shaker for $1 \mathrm{~min}$, the absorbance of each well was measured at $440 \mathrm{~nm}$ against a blank control, using a Synergy 2 Multi-Mode Microplate Reader (BioTek, USA). 


\subsubsection{Cell differentiation and mineralization}

Cells were first cultured in $100 \mu \mathrm{l}$ of culture medium in a 96-well plate at a density of $1.5 \times 10^{4}$ cells $/ \mathrm{cm}^{2}$ for $24 \mathrm{~h}$. Then the culture medium was replaced with the sample extracts, and the cells were further cultured for 4 days to allow proliferation. Subsequently, differentiation media consisting of sample extracts supplemented with $10^{-8} \mathrm{M}$ dexamethasone (Sigma, USA), 50 $\mu \mathrm{g} / \mathrm{ml}$ ascorbic acid (Thermo Fisher Scientific, USA) and $8 \mathrm{mM} \beta$-glycerophosphate ( $\beta$-GP, MP Biomedicals, USA) were used to incubate cells for 21 days. Cell differentiation was determined as alkaline phosphatase (ALP) activity, and mineralization was characterized by calcification of the extracellular matrix (ECM). 20\% Sr1 and 5\% Sr1 extracts, which were diluted from the $\mathrm{Sr} 1$ extracts, were included in the study. Meanwhile, to help analyze the results, $\alpha$-MEM medium containing $\mathrm{Zn}^{2+}$ at the same concentration as that of $\mathrm{Sr} 1$ extract (denoted as $100 \% \mathrm{Zn}$ ), and the

diluted $20 \% \mathrm{Zn}$ and $5 \% \mathrm{Zn}$ media were used in a parallel experiment. $\mathrm{Zn}^{2+}$ was supplemented by adding certain volume of a highly concentrated (1000x) and sterilized $\mathrm{ZnCl}_{2}$ (Sigma, USA) solution.

\subsubsection{Alkaline phosphatase activity}

For ALP activity study, cells were rinsed twice with PBS and stored overnight at $-70{ }^{\circ} \mathrm{C}$. After thawing the cells to room temperature (RT), $150 \mu \mathrm{l}$ of $1 \times$ CyQUANT cell lysis buffer (Invitrogen, USA) was added to each well. Cells were incubated in lysis buffer for $5 \mathrm{~min}$, followed by gentle pipetting and sonication. The cell lysate was transferred to microcentrifuge tubes and centrifuged at $12,000 \mathrm{rpm}$ for $3 \mathrm{~min}$ at $4{ }^{\circ} \mathrm{C}$. The supernatant was collected for the evaluation of ALP activity and total protein content. ALP activity was characterized as the amount of p-nitrophenol (pNP) produced on the hydrolysis of p-nitrophenyl phosphate (pNPP) in the presence of ALP as catalyst. Briefly, $50 \mu \mathrm{l}$ of each supernatant and $50 \mu \mathrm{l}$ of 1-step pNPP 
(Pierce, USA) were added into a 96-well plate and mixed well. After 60-min incubation at RT, 20 $\mu \mathrm{l}$ of $2 \mathrm{M} \mathrm{NaOH}$ was added into each well to terminate the reaction, and the absorbance was measured at $405 \mathrm{~nm}$. ALP activity results were normalized to total protein contents, which were measured using a Micro BCA Protein Assay Reagent Kit (Pierce, USA). Briefly, $25 \mu$ l of each supernatant was pipetted into a 96-well plate, mixed with $200 \mu \mathrm{l}$ of BCA working reagent for 30 s by shaking, and then incubated for $30 \mathrm{~min}$ at $37{ }^{\circ} \mathrm{C}$. After cooling the plate to RT, the absorbance was recorded at $562 \mathrm{~nm}$.

\subsubsection{Calcification of extracellular matrix}

The calcification of ECM was characterized histochemically using Alizarin Red S (ARS) staining. Briefly, the cells were rinsed twice with PBS, and fixed with 4\% paraformaldehyde for $1 \mathrm{~h}$ at RT. Fixed cell layers were rinsed with PBS and stained in 2\% ARS solution (pH 4.2, adjusted with $2 \mathrm{M} \mathrm{NaOH}$ ) for $30 \mathrm{~min}$. Afterwards, the cell layers were rinsed with DI water for 4 times and viewed under an Eclipse TE300 inverted optical microscope (Nikon, Japan). For quantitative analysis of the percentage of the stained area to the entire well area, 12 images for each well were collected and analyzed using ImageJ software.

\subsection{Statistical analysis}

All data were reported in the form of means \pm standard errors of at least triplicates. Statistical comparisons were performed using the Student's $t$-test, with the significance level defined as $p<0.05$.

\section{Results}

\subsection{Surface characterization}

\subsubsection{Surface roughness}

The surface roughness values of the tested samples are listed in Table 1. As been polished 
identically, BMG samples possess roughness values which are similar to each other but smaller than that of AZ31B sample. The three-dimensional (3D) topography images and SEM images showing surface morphologies after polishing are displayed in Fig. S2 in Supplementary material. Grooves and ridges as a result of sandpaper polishing can be clearly observed on AZ31B sample, while less remarkable surface features are noticed on BMG samples. Thus, different BMG samples exhibit similar roughness, while AZ31B sample has a rougher surface.

\subsubsection{Surface wettability and SFE}

Surface wettability is an important factor that influences biological interactions including protein adsorption, cell adhesion and spreading [1]. The contact angles for different alloys and the SFE calculated according to the Owens-Wendt's equation are listed in Table 1 . The water contact angle for AZ31B sample is larger than those for BMG samples, and BMG samples with higher $\mathrm{Sr}$ contents possess smaller water contact angles. The water contact angles for all samples are smaller than the Berg limit $\left(\theta=65^{\circ}\right)$, thus they are all hydrophilic [26]. Besides, BMG samples exhibit higher SFE than that of AZ31B sample, and BMG samples with higher $\mathrm{Sr}$

content show higher SFE. All alloys possess SFE higher than $50 \mathrm{mN} / \mathrm{m}^{2}$, which meets the theoretical limit of SFE for biomedical metallic materials [27].

\subsection{Cellular behaviors}

\subsubsection{Cell adhesion and morphology}

MC3T3-E1 pre-osteoblasts are anchorage-dependent cells, and good cell adhesion is the basis for further proliferation. SEM images showing cell morphologies after 4-h incubation on AZ31B and BMG samples are displayed in Fig. 1. From a general view of the column-1 images, a certain amount of cells with polygonal shape are attached onto all samples. Images in columns 2 and 3 are representative images of individual cell and high-magnification images showing 
cellular details, respectively. It is clearly seen that cells on BMG samples, compared with those on AZ31B samples, have better cytoplasmic extension and more amounts of lamellipodia and filopodia that are essential for cell migration and sensing [28]. Meanwhile, as shown in column-3 images, a great number of ruptured filopodia are seen on AZ31B samples, while only few ruptured ones are detected on BMG samples, which could be related to the cell fixation and dehydration. Due to the poor corrosion resistance, AZ31B samples would be corroded and the surface would crack in the fixation and dehydration media. After cells had been fixed onto the surface, the subsequent cracking would tear apart the fixed filopodia and even the cell body, which is indicated by the red arrows in Fig. 1m. For BMG samples, the good corrosion resistance would help the samples survive the fixation and dehydration, and negligible influence would be posed to the fixed cells. The numbers of cells attached onto different alloys are summarized in Fig. 1n. BMG samples have significantly higher amounts of attached cells than AZ31B sample, but no statistical difference can be distinguished among Sr0, Sr1 and Sr1.5 BMG samples.

\subsubsection{Sample extracts analysis}

The $\mathrm{pH}$ values and ion concentrations of the sample extracts are displayed in Fig. 2. AZ31B extract possesses a higher $\mathrm{pH}$ value than BMG extracts (Fig. 2a), suggesting that more hydroxyl

ions were generated from the metal-water reactions $\left(\mathrm{M}+2 \mathrm{H}_{2} \mathrm{O} \rightarrow \mathrm{M}^{2+}+2 \mathrm{OH}^{-}+\mathrm{H}_{2}, \mathrm{M}\right.$ represents metallic elements) during the immersion of AZ31B alloy. As shown in Fig. 2b, AZ31B extract contains a considerably higher concentration of $\mathrm{Mg}$ ion than BMG extracts, which can be ascribed to the high $\mathrm{Mg}$ content and inferior corrosion resistance of AZ31B alloy. Three BMG extracts exhibit similar $\mathrm{pH}$ and $\mathrm{Mg}$ ion concentrations, while $\mathrm{Sr} 1$ and $\mathrm{Sr} 1.5$ extracts contain lower $\mathrm{Ca}$ but higher $\mathrm{Zn}$ ion concentrations than $\mathrm{Sr} 0$ extract. The $\mathrm{Al}$ and $\mathrm{Mn}$ ion concentrations of AZ31B extract are shown in Fig. S3 in Supplementary material. 


\subsubsection{Cell viability}

Good cell viability indicates the high possibility of the survival of cells in a new environment. Live/dead staining images indicating cell viability in sample extracts are displayed in Fig. 3. Dead and unhealthy round-shaped cells are only observed for the cytotoxic positive control. Cells in sample extracts are viable with healthy polygonal/spindle cell shape, and no significant difference in cell numbers can be qualitatively noticed between the negative control and sample extracts. This suggests high viability of cells exposed to sample extracts.

\subsubsection{Cell proliferation}

The proliferation of pre-osteoblasts is an important basis for further osteogenic function, like differentiation and mineralization. The WST-1 assay results that correspond to cell proliferation are presented in Fig. 4. In all sample extracts, cells divide and proliferate continuously, as indicated by the gradually increased absorbance from days 1 to 5 . At day 1 , the significantly lower absorbance is recorded for all sample extracts in comparison with that for the negative control. While at day 3, the absorbance for BMG extracts is higher while the absorbance for AZ31B extract is still lower than that for the negative control. Besides, BMG extracts show lower absorbance than AZ31B extract at day 1, but exhibit higher values after day 3. After 5-day culture, the proliferation for AZ31B extract is somewhat higher than that for the negative control, but inferior to that for BMG extracts. There is no significant difference in the cell proliferation for $\mathrm{Sr} 0, \mathrm{Sr} 1$ and $\mathrm{Sr} 1.5 \mathrm{BMG}$ extracts at each time point.

\subsubsection{Cell differentiation and mineralization in sample extracts}

Cell differentiation from pre-osteoblasts to osteoblasts reveals the cellular osteogenic function, and osteoblasts will secrete ALP to prepare for mineralization. During mineralization, calcium deposits, normally calcium phosphates will be formed, showing as the calcification of 
ECM. Afterwards, calcium phosphates will evolve into hydroxyapatite, which is the main inorganic composition of bones. The cell differentiation is characterized by ALP activity. Figure 5 presents the ALP activities that are normalized to total protein contents. Compared with negative control, significant decreases in ALP activity are observed for the undiluted sample extracts. While for Sr1 extracts in different concentrations, an apparently increased ALP activity is detected for $20 \% \mathrm{Sr} 1$ extract in comparison with that for $100 \% \mathrm{Sr} 1$ extract, and 5\% $\mathrm{Sr} 1$ extract exhibits a further elevated ALP activity, which is slightly higher than that for negative control.

Cell mineralization is characterized by staining the calcium deposits produced by osteoblasts using ARS solution. The photograph of the stained cell layers is presented in Fig. 6a. Clear red ARS-staining is observed for the negative control, whereas for the undiluted sample extracts, stained cell layer is unobservable. As for the diluted 20\% Sr1 and 5\% Sr1 extracts, ARS-stained areas are noticed. The percentages of stained area to entire well area for each tested medium are illustrated in Fig. 6b, and the corresponding representative optical microscope (OM) images are presented in Fig. S4 in Supplementary material. The cell layer grown in negative control shows a stained area with a percentage of about $92 \%$, while much lower percentage values are obtained for undiluted sample extracts. Significant enhancement in mineralization is seen with decreasing the $\mathrm{Sr} 1$ extract concentration to $20 \%$, and $5 \%$ Sr1 extract exhibits a stained area slightly larger than that for the negative control.

\subsubsection{Cell differentiation and mineralization in $\mathrm{Zn}^{2+}$-containing media}

Normalized ALP activities indicating cell differentiation in $\mathrm{Zn}^{2+}$-containing media are illustrated in Fig. 7. Clearly, $\mathrm{Zn}^{2+}$ at the tested concentrations shows inhibitory effects on cell differentiation, as the lower ALP activities for $\mathrm{Zn}^{2+}$-containing media in comparison with that for the negative control. The $100 \% \mathrm{Zn}^{2+}$ addition to culture medium introduces a significant 
decrease in cell differentiation, but considerable enhancements in differentiation accompany the reduction in $\mathrm{Zn}^{2+}$ concentration.

The photograph of the ARS-stained cell layer grown in $\mathrm{Zn}^{2+}$-containing media is shown in Fig. 8a. Dissimilar to the normal ARS staining for the negative control, $100 \% \mathrm{Zn}$ medium shows negligible staining indicating poor cell mineralization, while clear staining is observed for $20 \%$ $\mathrm{Zn}$ and $5 \% \mathrm{Zn}$ media. The percentages of stained area to entire well area are displayed in Fig. 8b, and the corresponding representative OM images are shown in Fig. S5 in Supplementary material. Although the stained area for $100 \% \mathrm{Zn}$ medium is quite small, $20 \% \mathrm{Zn}$ and $5 \% \mathrm{Zn}$ media with diluted $\mathrm{Zn}^{2+}$ concentration exhibit large stained area that is close to that for the negative control.

\section{Discussion}

\subsection{In vitro biocompatibility}

Both direct and indirect cell-culture experiments were employed to study the in vitro biocompatibility of $\mathrm{Mg}-\mathrm{Zn}-\mathrm{Ca}-\mathrm{Sr}$ BMGs. Direct cell-culture experiment is to incubate cells directly on the sample surface in normal culture medium, and study the cellular behavior to assess the biocompatibility of the sample. While in the indirect cell-culture experiment, sample extract is prepared first and replaces the normal culture medium to incubate cells. The biocompatibility of the sample is assessed by analyzing the cellular behavior in the sample extract. Mg-based BMGs aim to serve as biodegradable orthopedic implants, and during the bone remodeling period, qualified implant should get a solid connection with the bone. In the direct cell-culture experiment, if bone cells could get attached to the material surface and proliferate normally, it could indicate the bioactive reaction between the implant and the bone, and this in vivo bioactive reaction is favorable for bone remodeling. So, direct cell-culture experiment was 
used to study cell adhesion onto BMGs. Besides, during the degradation, since the surface of Mg-based BMGs would change continuously and the outer part would degrade continuously, it is difficult to study long-term cellular behaviors, like long-time proliferation, differentiation and mineralization, through direct cell-culture experiment. Meanwhile, released ions resulted from alloy degradation, which may be the main degradation product of Mg alloys, could influence the cells and tissues around the alloy. Thus, we also used indirect cell-culture experiment to particularly study the effects of released ions on cellular behaviors.

As demonstrated by the indirect cell-culture study, Mg-Zn-Ca-Sr BMGs exhibited similar cytotoxicity of Grade 0 (no toxicity) to AZ31B alloy, according to ISO 10993-5 [29]. Despite of the comparable cytotoxicity, influences on cell proliferation of different alloy extracts were inconsistent. At day 1, adverse effects of the variation in $\mathrm{pH}$ and ion concentrations of the sample extracts on cell proliferation were noticed. Considering that there was no dead cell observed in the cell-viability assay, it could be deduced that the changes in environment might not kill cells but lower their metabolic activity to proliferate. After the 3-day culture, cells in AZ31B extract shared similar proliferation to those in the negative control, while more cells were detected in BMG extracts. This suggested that cells in sample extracts became adapted to the environment and exhibited a proliferation capability slightly superior to those in the negative control with the prolonged culture time. It was reported that $\mathrm{IC}_{50}$ of $\mathrm{Zn}^{2+}$ for MC3T3-E1 cells was about $5.9 \mathrm{mg} / \mathrm{L}$, and only about $20 \%$ cells could survive in medium bearing $12 \mathrm{mg} / \mathrm{L} \mathrm{Zn}^{2+}$ [30]. Since all BMG extracts contained $\mathrm{Zn}^{2+}$ higher than $11 \mathrm{mg} / \mathrm{L}$, the enhanced cell proliferation in BMG extracts could be ascribed to the stimulatory effects of the exogenous $\mathrm{Mg}^{2+}$ and $\mathrm{Sr}^{2+}[31,32]$, which helped counteract the adverse effect of $\mathrm{Zn}^{2+}$.

Although cell proliferation in sample extracts was slightly higher than that in negative 
control, cell differentiation in sample extracts was much inferior to that in negative control, while this discrepancy significantly diminished with decreasing the concentration of sample extract. Table S1 in Supplementary material presents the ion concentrations of the sample extracts and the diluted 20\% Sr1 and 5\% Sr1 extracts. It was manifested by the cell differentiation test using $\mathrm{Zn}^{2+}$-containing media that $\mathrm{Zn}^{2+}$ at high concentration posed an inhibitory effect on differentiation, while increased differentiation accompanied the decreased $\mathrm{Zn}^{2+}$ concentration. Thus, for BMG extracts, the suppressed differentiation could be mainly ascribed to the high $\mathrm{Zn}^{2+}$ concentrations. While for AZ31B extract, the considerable $\mathrm{Mg}^{2+}$ should be responsible for the low level of differentiation, as $\mathrm{Mg}^{2+}$ at high concentration was reported to behave detrimentally to MC3T3-E1 cell differentiation [33]. It is worth noticing that ALP activity for 5\% Sr1 extract was slightly higher than that for $5 \% \mathrm{Zn}$ medium, which could be attributed to the stimulatory effects of $\mathrm{Mg}^{2+}$ and $\mathrm{Sr}^{2+}$ at proper concentrations [34, 35].

ALP is known to facilitate cell mineralization by generating inorganic phosphate from substrates such as $\beta$-GP [36, 37]. After cell differentiation, ALP would be synthesized and secreted by osteogenic osteoblasts, and catalyzed the hydrolysis of $\beta$-GP to provide inorganic phosphate for mineralization. As revealed by the ARS-staining results, sample extracts were unable to support normal mineralization, and the levels of mineralization, which were characterized by the percentages of ARS-stained area, were in line with the levels of corresponding differentiation. In view of the low level of cell differentiation in sample extracts, the amount of ALP secreted by cells in sample extracts was lower than that in negative control, resulting in the low level of mineralization. The ions in sample extracts, which differed a lot in concentration from those in negative control, should also be responsible for the inferior mineralization. The detrimental effect of $\mathrm{Zn}^{2+}$ at high concentration on mineralization was 
indicated by the negligible ARS-staining of cell layer in $100 \% \mathrm{Zn}$ medium. Meanwhile, it has been reported about the inhibition of $\mathrm{Zn}^{2+}(>1 \mathrm{mg} / \mathrm{L})$ on ALP activity [38], and the adverse effect of $\mathrm{Zn}^{2+}(0.51 \mathrm{ppm})$ on human osteoblast cell mineralization [39]. Thus, the high concentrations of $\mathrm{Zn}^{2+}$ should take responsibility for the inferior mineralization in BMG extracts. Arise et al. [40] illustrated that $\mathrm{Mg}^{2+}$ below $4 \mathrm{mM}$ had promotive effect on ALP activity while adverse influence was observed on further increasing $\mathrm{Mg}^{2+}$ concentration. Serre et al. [41] reported that large amounts of $\mathrm{Mg}^{2+}$ inhibited the osteoblast phenotype. Therefore, the high amount of $\mathrm{Mg}^{2+}$ was supposed to account for the inferior mineralization in AZ31B extract.

Results of the direct cell-culture test showed that, compared with AZ31B alloy, BMGs had higher amounts of attached cells with a better cytoplasmic extension. Since samples were polished to the same surface finish and an indistinctive difference in the roughness between AZ31B alloy and BMGs was detected, the effect of roughness on cell adhesion could be eliminated. The effect of SFE on cell adhesion could also be neglected, due to the similar cell adhesion among Sr0, Sr1 and Sr1.5 BMGs, although their SFE was appreciably different. The inferior corrosion resistance of AZ31B alloy to that of BMGs, which was indicated by the much higher $\mathrm{pH}$ and $\mathrm{Mg}^{2+}$ concentration of AZ31B extract than those of BMG extracts, should be responsible for the inferior cell adhesion and spreading. The weak corrosion resistance of AZ31B alloy resulted in severe hydrogen evolution, localized alkalization surrounding the sample, and surface cracks. The severe hydrogen evolution, which could be observed when AZ31B samples were immersed in $\alpha$-MEM, deteriorated the cell adhesion and spreading by affecting cellular metabolic activity and altering surface condition if bubbles gathered onto the surface. Localized alkalization would also reduce cellular activity and be adverse to cellular behavior. Surface cracks made the substrate surface changeable and inappropriate for cell adhesion and spreading. 
Direct and indirect cell-culture tests are both well-established methods to study the in vitro biocompatibility, while inconsistent results could appear. In the direct test, AZ31B alloy was much less capable of supporting cell adhesion than BMGs, while in the indirect condition, AZ31B extract exhibited almost comparable cytocompatibility to BMG extracts. Similarly, Gu et al. [18] reported the reduced cell viability in direct assay than that in indirect test for pure $\mathrm{Mg}$ and $\mathrm{Mg}_{70} \mathrm{Zn}_{25} \mathrm{Ca}_{5} \mathrm{BMG}$, while the difference for the more corrosion-resistant $\mathrm{Mg}_{66} \mathrm{Zn}_{30} \mathrm{Ca}_{4}$ BMG was limited. It is known that cells are very susceptible to environmental changes, such as the variation in $\mathrm{pH}$ and ion concentrations, hydrogen evolution, insoluble corrosion products, disintegrated particles and changeable substrate surface introduced by corrosion of $\mathrm{Mg}$ alloys [18, 42]. Under direct test circumstances, cells encounter all these environmental fluctuations directly, which could be very harsh for cells to survive, especially in the case of low corrosion-resistant materials. While in the indirect test condition, since the hydrogen evolution, insoluble corrosion products, disintegrated particles and changeable substrate surface have been expelled during the extract preparation, cells only have to suffer the variation in hydroxyl ions and metallic ions. Accordingly, cells may behave much better and healthier in the indirect test in comparison with direct test, and this accounts for the case of low corrosion-resistant AZ31B alloy.

4.2 Comparison of corrosion/degradation behavior and biocompatibility among biodegradable $M g-, C a-$ and Sr-based BMGs

Mg-, Ca- and Sr-based BMGs have received considerable attention as potential biodegradable orthopedic implants, owing to the highly active nature and biocompatibility of the base elements, and good mechanical properties [17-21, 43-48]. The biodegradable application-related parameters of representative $\mathrm{Mg}$-, $\mathrm{Ca}$ - and $\mathrm{Sr}$-based BMGs are listed in Table 2. 


\subsubsection{Corrosion/degradation behavior}

The rapid corrosion/degradation rate is the major concern against the biodegradable applications of crystalline Mg alloys, while this concern could be mitigated for BMGs. Mg-based BMGs with Zn contents higher than 28 at.\% exhibited distinctly reduced hydrogen evolution and lower corrosion rates than almost all of the crystalline $\mathrm{Mg}$ alloys, owing to the formation of $\mathrm{Zn}(\mathrm{OH})_{2} / \mathrm{ZnO} / \mathrm{ZnCO}_{3}$ protective layer $[8,17,18,20]$. As for $\mathrm{Ca}_{65} \mathrm{Mg}_{15} \mathrm{Zn}_{20} \mathrm{BMG}$, the slightly soluble $\mathrm{Ca}(\mathrm{OH})_{2}$ and the deficient $\mathrm{Zn}$ content made it difficult to form an oxidation layer as protective as that for Mg-based BMGs. Thus, the highly active nature of base element $\mathrm{Ca}$ and the low content of $\mathrm{Zn}$ should account for the rough and porous surface after immersion and the unsatisfactory degradation rate of $\mathrm{Ca}_{65} \mathrm{Mg}_{15} \mathrm{Zn}_{20} \mathrm{BMG}$ that totally dissolved within $3 \mathrm{~h}$ in Hank's solution [44]. Worse than Ca-based $\mathrm{BMG}, \mathrm{Sr}_{60} \mathrm{Mg}_{18} \mathrm{Zn}_{22} \mathrm{BMG}$ presented a catastrophic degradation, which was the fully degradation within $1 \mathrm{~min}$ in water [48]. The incorporation of $\mathrm{Yb}$ and $\mathrm{Cu}$ and the increase in $\mathrm{Zn}$ content could prominently retard the degradation of $\mathrm{Ca}$ - and Sr-based BMGs to a comparable state to the most corrosion resistant crystalline Mg alloys. From the view of the strength reduction caused by degradation, the enhanced corrosion resistance and high mechanical strength make Mg-, Ca- and Sr-based BMGs suitable for biodegradable applications.

\subsubsection{Biocompatibility}

The biocompatibility of biodegradable BMGs has a strong correlation with their corrosion/degradation behavior, since the degradation products influence cellular responses significantly. The Mg-Zn-Ca-Sr BMGs with low degradation rates showed slight promotion of cell proliferation and good capability of supporting cell adhesion. Gu et al. [18] studied the responses of MG63 and L929 cells to $\mathrm{Mg}_{66} \mathrm{Zn}_{30} \mathrm{Ca}_{4}$ and $\mathrm{Mg}_{75} \mathrm{Zn}_{25} \mathrm{Ca}_{5}$ BMGs and found that, 
compared with the lower corrosion-resistant $\mathrm{Mg}_{75} \mathrm{Zn}_{25} \mathrm{Ca}_{5} \mathrm{BMG}$, cells cultured in $\mathrm{Mg}_{66} \mathrm{Zn}_{30} \mathrm{Ca}_{4}$ BMG extract exhibited higher proliferation, which was ascribed to the difference in $\mathrm{pH}$ and ion concentrations of the extracts. For $\mathrm{Ca}_{65} \mathrm{Mg}_{15} \mathrm{Zn}_{20} \mathrm{BMG}$ that exhibited rapid degradation, MG63 cells cultured in $30 \%$ extract presented comparable proliferation to that in negative control, but with increasing the extract concentration, cell proliferation deteriorated dramatically [44]. While for $\mathrm{Ca}_{20} \mathrm{Mg}_{20} \mathrm{Zn}_{20} \mathrm{Sr}_{20} \mathrm{Yb}_{20}, \mathrm{Ca}_{32} \mathrm{Zn}_{38} \mathrm{Mg}_{12} \mathrm{Yb}_{18}$ and $\mathrm{Sr}_{40} \mathrm{Mg}_{20} \mathrm{Zn}_{15} \mathrm{Yb}_{20} \mathrm{Cu}_{5}$ BMGs which had low degradation rates, MG63 cells cultured in 100\% extract exhibited comparable proliferation to that in negative control, indicating that high corrosion resistance could reduce the environmental changes introduced by alloy degradation and therefore improve the biocompatibility [45-47].

Several elements including $\mathrm{Zn}, \mathrm{Yb}$ and $\mathrm{Cu}$ were alloyed in the $\mathrm{Mg}-$ - $\mathrm{Ca}-$ and $\mathrm{Sr}-\mathrm{based} \mathrm{BMGs}$ for the main purpose of improving corrosion resistance. But the amounts of alloying elements should be carefully considered to avoid or alleviate possible detrimental effects on biocompatibility, which are caused by the released ions due to degradation. $\mathrm{Zn}^{2+}$ and $\mathrm{Cu}^{2+}$ exhibited $\mathrm{IC}_{50} \mathrm{~S}$ of $9 \times 10^{-2} \mathrm{mM}$ and $1.59 \times 10^{-2} \mathrm{mM}$ for MC3T3-E1 cells, respectively [30], and the $\mathrm{IC}_{50}$ of $\mathrm{Yb}^{3+}$ for vascular smooth muscle cells was about $1.8 \times 10^{-2} \mathrm{mM}$ [49]. $\mathrm{Zn}^{2+}$ at high concentration showed inhibitory effects on differentiation of pre-osteoblasts and mineralization of osteoblasts, and subsequently, could affect the bone formation. Besides, $\mathrm{Zn}^{2+}$ at high concentration was reported to be neurotoxic and retard bone development [8]. $\mathrm{Yb}$ addition in the low concentration range did not pose significant change to the proliferation of human cells, whereas high concentration of $\mathrm{Yb}$ caused the decrease in cell proliferation and the upregulation of inflammatory genes [49]. Excessive $\mathrm{Cu}$ was toxic and could cause lipid peroxidation in membranes, direct oxidation of proteins, and cleavage of DNA and RNA molecules [50]. Consequently, although alloying contributes to the retarded corrosion/degradation, contents of 
the alloying elements should be carefully considered in order to achieve an optimal property profile.

It is meaningful if tunable degradation can be achieved, since the required healing time for different kinds of patients is not identical, such as that it takes longer time for old-aged or osteoporotic patients than young adult patients to recover. In view of the wide degradation rate window for $\mathrm{Mg}-, \mathrm{Ca}-$ and $\mathrm{Sr}-$ based $\mathrm{BMGs}$, it is feasible to tailor the degradation behavior by using BMGs with different base elements and adjusting alloy compositions. Besides, since the material integrity deteriorates during degradation, which would affect mechanical properties, the mechanical properties as a function of immersion time should be investigated to have a clear understanding on the effects of degradation on mechanical properties.

\section{Conclusions}

In the present study, the feasibility of $\mathrm{Mg}-\mathrm{Zn}-\mathrm{Ca}-\mathrm{Sr} \mathrm{BMGs}$ to serve as orthopedic implants was investigated by in vitro cell-culture experiments, and the favorable biocompatibility of $\mathrm{Mg}-\mathrm{Zn}-\mathrm{Ca}-\mathrm{Sr}$ BMGs was illustrated. Based on the results and discussion, the following conclusions were drawn.

(1) The Mg-Zn-Ca-Sr BMGs were much more capable of supporting cell adhesion and spreading than AZ31B alloy, which was ascribed to the higher corrosion resistance and the corresponding lower environmental fluctuations.

(2) The Mg-Zn-Ca-Sr BMG extracts showed no cytotoxicity to and slightly stimulated the proliferation of pre-osteoblasts.

(3) The 100\% BMG extract exhibited inhibitory effects on cell differentiation and mineralization, while with decreasing the extract concentration, the adverse influences were diminished and 5\% Sr1 extract could slightly stimulate the cell differentiation and 
mineralization. The high concentrations of $\mathrm{Zn}^{2+}$ in BMG extracts were suggested to be responsible for the inferior cell differentiation and mineralization.

(4) Biodegradable BMGs possess suitable corrosion/degradation behavior and good biocompatibility, suggesting their potential for biomedical applications. Further studies on controlling the ion release of unfavorable elements and degradation-related mechanical properties are required.

\section{Acknowledgements}

H.F.L., S.J.P. and T.Z. acknowledge the financial support by the National Natural Science Foundation of China (No. 51161130526), and Natural Science Foundation of Beijing (No. 2132045). W.H. and P.K.L. appreciate the US National Science Foundation (NSF) for support (CMMI-1100080). P.K.L. acknowledges the financial support by the Department of Energy, Office of Fossil Energy, National Energy Technology Laboratory (DE-FE-0008855 and DE-FE-0024054). 


\section{References}

[1] B.D. Ratner, A.S. Hoffman, F.J. Schoen, J.E. Lemons, Biomaterials science: an introduction to materials in medicine, 2nd ed, Academic press, San Diego, California, USA, 2004.

[2] G. Mani, M.D. Feldman, D. Patel, C.M. Agrawal, Coronary stents: A materials perspective, Biomaterials 28 (2007) 1689-1710.

[3] B. O'Brien, W. Carroll, The evolution of cardiovascular stent materials and surfaces in response to clinical drivers: A review, Acta Biomater. 5 (2009) 945-958.

[4] J. Nagels, M. Stokdijk, P.M. Rozing, Stress shielding and bone resorption in shoulder arthroplasty, J. Shoulder Elbow Surg. 12 (2003) 35-39.

[5] F. Witte, N. Hort, C. Vogt, S. Cohen, K.U. Kainer, R. Willumeit, F. Feyerabend, Degradable biomaterials based on magnesium corrosion, Curr. Opin. Solid State Mater. Sci. 12 (2008) 63-72.

[6] M.P. Staiger, A.M. Pietak, J. Huadmai, G. Dias, Magnesium and its alloys as orthopedic biomaterials: A review, Biomaterials 27 (2006) 1728-1734.

[7] F. Witte, The history of biodegradable magnesium implants: A review, Acta Biomater. 6 (2010) 1680-1692.

[8] Y.F. Zheng, X.N. Gu, F. Witte, Biodegradable metals, Mater. Sci. Eng. R-Rep. 77 (2014) $1-34$.

[9] K. Rezwan, Q.Z. Chen, J.J. Blaker, A.R. Boccaccini, Biodegradable and bioactive porous polymer/inorganic composite scaffolds for bone tissue engineering, Biomaterials 27 (2006) 3413-3431.

[10] M. Wang, Developing bioactive composite materials for tissue replacement, Biomaterials 24 (2003) 2133-2151.

[11] J. Han, P. Wan, Y. Ge, X. Fan, L. Tan, J. Li, K. Yang, Tailoring the degradation and biological response of a magnesium-strontium alloy for potential bone substitute application, Mater. Sci. Eng. C 58 (2016) 799-811.

[12] Y. Ren, H. Zhou, M. Nabiyouni, S.B. Bhaduri, Rapid coating of AZ31 magnesium alloy 
with calcium deficient hydroxyapatite using microwave energy, Mater. Sci. Eng. C 49 (2015) 364-372.

[13] J. Zhang, Z. Wen, M. Zhao, G. Li, C. Dai, Effect of the addition CNTs on performance of CaP/chitosan/coating deposited on magnesium alloy by electrophoretic deposition, Mater. Sci. Eng. C 58 (2016) 992-1000.

[14] W. Sun, G. Zhang, L. Tan, K. Yang, H. Ai, The fluoride coated AZ31B magnesium alloy improves corrosion resistance and stimulates bone formation in rabbit model, Mater. Sci. Eng. C 63 (2016) 506-511.

[15] T. Hanas, T.S. Sampath Kumar, G. Perumal, M. Doble, Tailoring degradation of AZ31 alloy by surface pre-treatment and electrospun PCL fibrous coating, Mater. Sci. Eng. C 65 (2016) 43-50.

[16] W.H. Wang, C. Dong, C.H. Shek, Bulk metallic glasses, Mater. Sci. Eng. R-Rep. 44 (2004) 45-89.

[17] B. Zberg, P.J. Uggowitzer, J.F. Loffler, MgZnCa glasses without clinically observable hydrogen evolution for biodegradable implants, Nat. Mater. 8 (2009) 887-891.

[18] X.N. Gu, Y.F. Zheng, S.P. Zhong, T.F. Xi, J.Q. Wang, W.H. Wang, Corrosion of, and cellular responses to Mg-Zn-Ca bulk metallic glasses, Biomaterials 31 (2010) 1093-1103.

[19] W.Y. Chan, K.S. Chian, M.J. Tan, In vitro metal ion release and biocompatibility of amorphous Mg67Zn28Ca5 alloy with/without gelatin coating, Mater. Sci. Eng. C 33 (2013) 5019-5027.

[20] H.F. Li, S.J. Pang, Y. Liu, L.L. Sun, P.K. Liaw, T. Zhang, Biodegradable Mg-Zn-Ca-Sr bulk metallic glasses with enhanced corrosion performance for biomedical applications, Mater. Des. 67 (2015) 9-19.

[21] H. Li, Y. Liu, S. Pang, P.K. Liaw, T. Zhang, Corrosion fatigue behavior of a Mg-based bulk metallic glass in a simulated physiological environment, Intermetallics 73 (2016) 31-39.

[22] G. Chinga, P.O. Johnsen, R. Dougherty, E.L. Berli, J. Walter, Quantification of the 3D 
microstructure of SC surfaces, J. Microscopy 227 (2007) 254-265.

[23] D.K. Owens, R.C. Wendt, Estimation of surface free energy of polymers, J. Appl. Polym. Sci. 13 (1969) 1741-1747.

[24] L. Huang, Z. Cao, H.M. Meyer, P.K. Liaw, E. Garlea, J.R. Dunlap, T. Zhang, W. He, Responses of bone-forming cells on pre-immersed Zr-based bulk metallic glasses: Effects of composition and roughness, Acta Biomater. 7 (2011) 395-405.

[25] ISO 10993-12: Biological evaluation of medical devices-Part 12: Sample preparation and reference materials, International Organization for Standardization, Geneva, Switzerland, 2007. [26] E.A. Vogler, Structure and reactivity of water at biomaterial surfaces, Adv. Colloid Interface Sci. 74 (1998) 69-117.

[27] C.A. Haynes, W. Norde, Globular proteins at solid/liquid interfaces, Colloid Surf. B: Biointerfaces 2 (1994) 517-566.

[28] B. Alberts, A. Johnson, J. Lewis, D. Morgan, M. Raff, K. Roberts, P. Walter, Molecular biology of the cell, Sixth ed, Garland Science, Taylor \& Francis Group, New York, USA, 2015. [29] ISO 10993-5: Biological evaluation of medical devices-Part 5: Tests for in vitro cytotoxicity, International Organization for Standardization, Geneva, Switzerland, 2009.

[30] A. Yamamoto, R. Honma, M. Sumita, Cytotoxicity evaluation of 43 metal salts using murine fibroblasts and osteoblastic cells, J. Biomed. Mater. Res. 39 (1998) 331-340.

[31] Z.J. Li, X.N. Gu, S.Q. Lou, Y.F. Zheng, The development of binary Mg-Ca alloys for use as biodegradable materials within bone, Biomaterials 29 (2008) 1329-1344.

[32] M. Bornapour, N. Muja, D. Shum-Tim, M. Cerruti, M. Pekguleryuz, Biocompatibility and biodegradability of $\mathrm{Mg}-\mathrm{Sr}$ alloys: The formation of $\mathrm{Sr}$-substituted hydroxyapatite, Acta Biomater. 9 (2013) 5319-5330.

[33] H.M. Wong, S.L. Wu, P.K. Chu, S.H. Cheng, K.D.K. Luk, K.M.C. Cheung, K.W.K. Yeung, Low-modulus Mg/PCL hybrid bone substitute for osteoporotic fracture fixation, Biomaterials 34 (2013) 7016-7032. 
[34] R.W. Li, N.T. Kirkland, J. Truong, J. Wang, P.N. Smith, N. Birbilis, D.R. Nisbet, The influence of biodegradable magnesium alloys on the osteogenic differentiation of human mesenchymal stem cells, J. Biomed. Mater. Res. Part A 102 (2014) 4346-4357.

[35] E. Bonnelye, A. Chabadel, F. Saltel, P. Jurdic, Dual effect of strontium ranelate: Stimulation of osteoblast differentiation and inhibition of osteoclast formation and resorption in vitro, Bone 42 (2008) 129-138.

[36] M.D. Fallon, M.P. Whyte, S.L. Teitelbaum, Stereospecific inhibition of alkaline phosphatase by L-tetramisole prevents in vitro cartilage calcification, Lab. Invest. 43 (1980) 489-494.

[37] C.G. Bellows, J.N.M. Heersche, J.E. Aubin, Inorganic phosphate added exogenously or released from beta-glycerophosphate initiates mineralization of osteoid nodules in vitro, Bone Miner. 17 (1992) 15-29.

[38] R. Rej, J.P. Bretaudiere, Effects of metal ions on the measurement of alkaline phosphatase activity, Clin. Chem. 26 (1980) 423-428.

[39] N.S. Murni, M.S. Dambatta, S.K. Yeap, G.R.A. Froemming, H. Hermawan, Cytotoxicity evaluation of biodegradable $\mathrm{Zn}-3 \mathrm{Mg}$ alloy toward normal human osteoblast cells, Mater. Sci. Eng. C 49 (2015) 560-566.

[40] R.O. Arise, F.F. Davies, S.O. Malomo, Independent and interactive effects of $\mathrm{Mg} 2+$ and Co2+ on some kinetic parameters of rat kidney alkaline phosphatase, Sci. Res. Essays 3 (2008) 488-494.

[41] C.M. Serre, M. Papillard, P. Chavassieux, J.C. Voegel, G. Boivin, Influence of magnesium substitution on a collagen-apatite biomaterial on the production of a calcifying matrix by human osteoblasts, J. Biomed. Mater. Res. 42 (1998) 626-633.

[42] C.A. Grillo, F. Alvarez, M.A. Fernández Lorenzo de Mele, Degradation of bioabsorbable Mg-based alloys: Assessment of the effects of insoluble corrosion products and joint effects of alloying components on mammalian cells, Mater. Sci. Eng. C 58 (2016) 372-380.

[43] H.F. Li, S.J. Pang, Y. Liu, P.K. Liaw, T. Zhang, In vitro investigation of $\mathrm{Mg}-\mathrm{Zn}-\mathrm{Ca}-\mathrm{Ag}$ bulk 
metallic glasses for biomedical applications, J. Non-Cryst. Solids 427 (2015) 134-138.

[44] Y.B. Wang, X.H. Xie, H.F. Li, X.L. Wang, M.Z. Zhao, E.W. Zhang, Y.J. Bai, Y.F. Zheng, L. Qin, Biodegradable CaMgZn bulk metallic glass for potential skeletal application, Acta Biomater. 7 (2011) 3196-3208.

[45] H.F. Li, X.H. Xie, K. Zhao, Y.B. Wang, Y.F. Zheng, W.H. Wang, L. Qin, In vitro and in vivo studies on biodegradable CaMgZnSrYb high-entropy bulk metallic glass, Acta Biomater. 9 (2013) 8561-8573.

[46] W. Jiao, H.F. Li, K. Zhao, H.Y. Bai, Y.B. Wang, Y.F. Zheng, W.H. Wang, Development of CaZn based glassy alloys as potential biodegradable bone graft substitute, J. Non-Cryst. Solids 357 (2011) 3830-3840.

[47] H.F. Li, K. Zhao, Y.B. Wang, Y.F. Zheng, W.H. Wang, Study on bio-corrosion and cytotoxicity of a Sr-based bulk metallic glass as potential biodegradable metal, J. Biomed. Mater. Res. Part B 100B (2012) 368-377.

[48] K. Zhao, J.F. Li, D.Q. Zhao, M.X. Pan, W.H. Wang, Degradable Sr-based bulk metallic glasses, Scr. Mater. 61 (2009) 1091-1094.

[49] A. Drynda, N. Deinet, N. Braun, M. Peuster, Rare earth metals used in biodegradable magnesium-based stents do not interfere with proliferation of smooth muscle cells but do induce the upregulation of inflammatory genes, J. Biomed. Mater. Res. Part A 91A (2009) 360-369.

[50] H. Tapiero, D.M. Townsend, K.D. Tew, Trace elements in human physiology and pathology. Copper, Biomed. Pharmacother. 57 (2003) 386-398. 


\section{Figure captions:}

Fig. 1. (a-m) SEM images showing morphologies of attached MC3T3-E1 cells (scale bars for column 1, column 2 and image (m), and column 3 represent 100, 10 and $2 \mu \mathrm{m}$, respectively), and (n) numbers of cells attached onto $\mathrm{AZ31B}, \mathrm{Sr} 0, \mathrm{Sr} 1$ and $\mathrm{Sr} 1.5$ alloys after 4-h incubation (presented as percentages of the number of cells attached onto AZ31B alloy). Compared with AZ31B alloy, $* p<0.05$.

Fig. 2. (a) The $\mathrm{pH}$ values and (b) ion concentrations of the extracts of AZ31B, Sr0, Sr1 and Sr1.5 alloys.

Fig. 3. Fluorescent images showing the viable (green) and dead (red) MC3T3-E1 cells after 1-day incubation in sample extracts. Scale bars represent $100 \mu \mathrm{m}$.

Fig. 4. Absorbance indicating the proliferation of MC3T3-E1 cells cultured in sample extracts for 1, 3 and 5 days. Compared with the negative control, ${ }^{*} p<0.05$.

Fig. 5. Normalized ALP activities indicating cell differentiation in sample extracts. Results are presented as percentages of that for negative control. Compared with negative control, $* * p<$ 0.01; compared with Sr1, \#\#p $<0.01$; compared with $20 \% \operatorname{Sr} 1, \wedge \wedge p<0.01$.

Fig. 6. Cell mineralization in sample extracts: (a) photograph of ARS-stained cell layers, and (b) percentages of stained area to entire well area. Compared with negative control, $* * p<0.01$; compared with $\operatorname{Sr} 1, \# \# p<0.01$.

Fig. 7. Normalized ALP activities indicating cell differentiation in $\mathrm{Zn}^{2+}$-containing media. Results are presented as percentages of that for negative control. Compared with negative control, ${ }^{*} p<0.05,{ }^{*} p<0.01$; compared with $100 \% \mathrm{Zn}, \# \# p<0.01$; compared with $20 \% \mathrm{Zn}, \wedge p<0.05$. 
Fig. 8. Cell mineralization in $\mathrm{Zn}^{2+}$-containing media: (a) photograph of ARS-stained cell layers, and (b) percentages of stained area to entire well area. Compared with negative control, ** $p<$ 0.01 ; compared with $100 \% \mathrm{Zn}, \# \# p<0.01$. 
Column 1

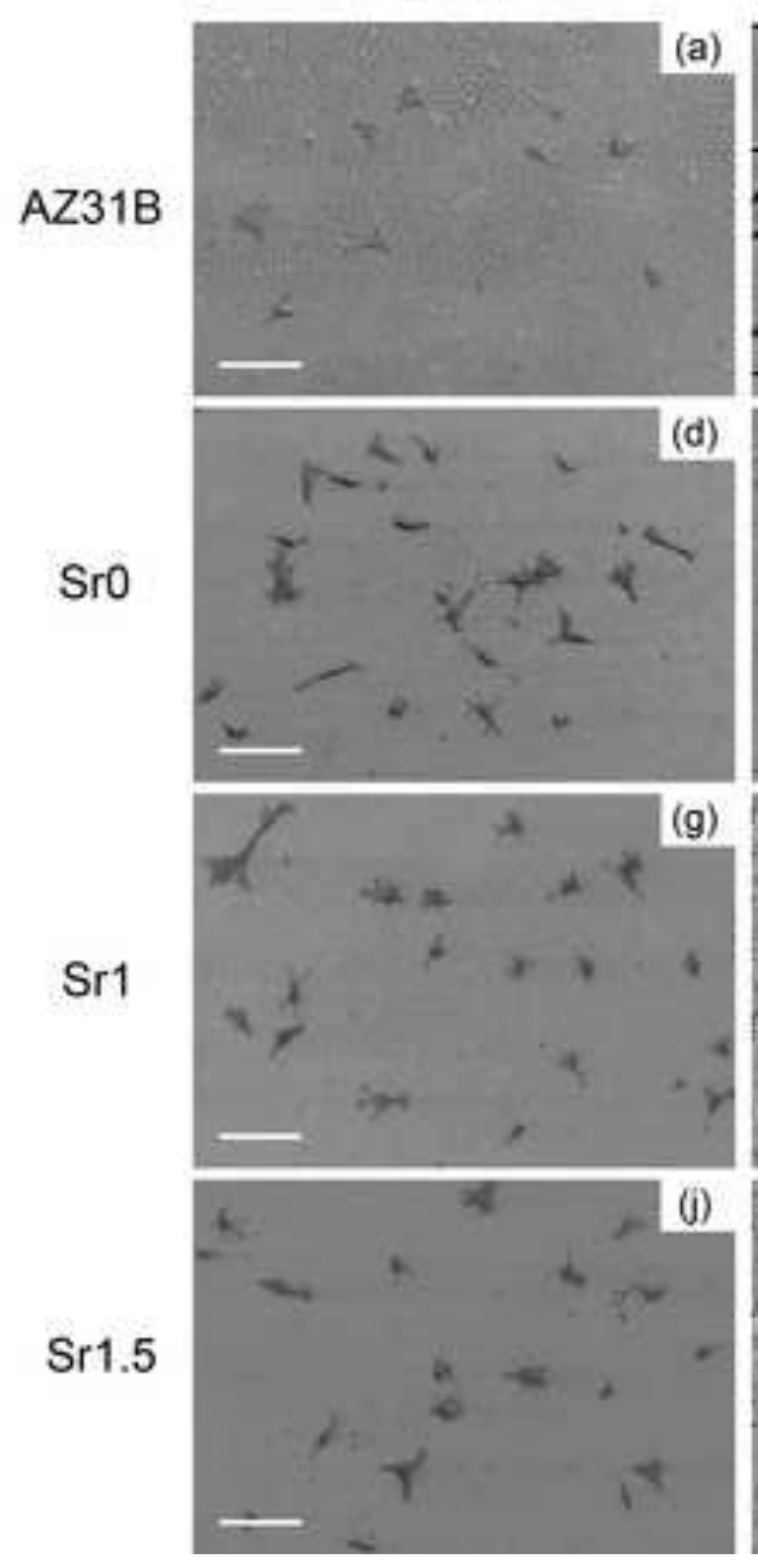

Column 2

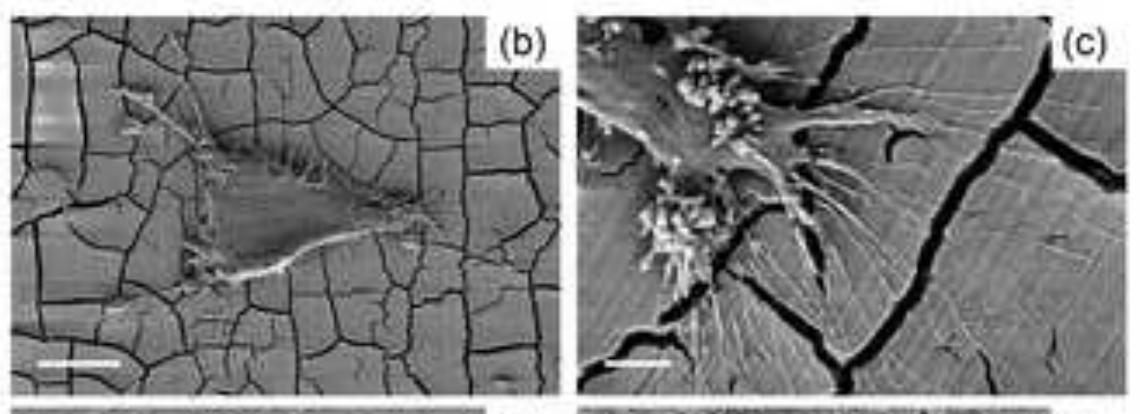

(e)

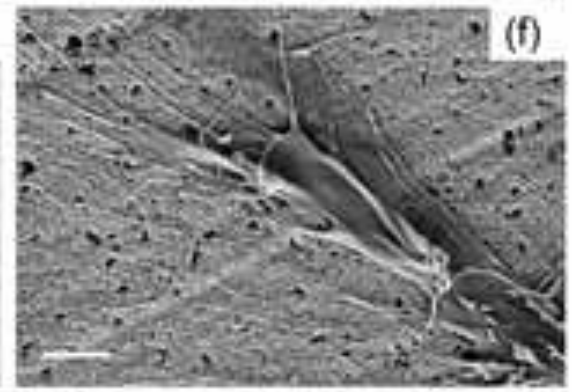

(h)

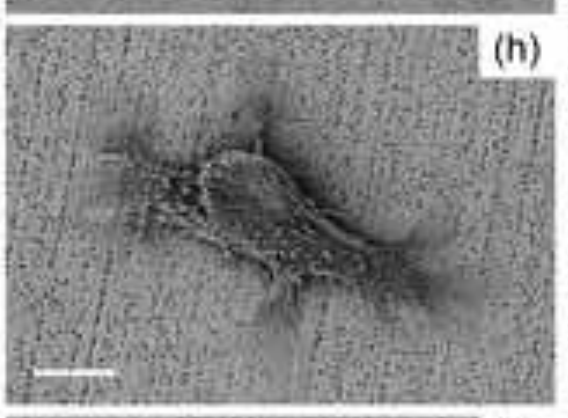

(k)
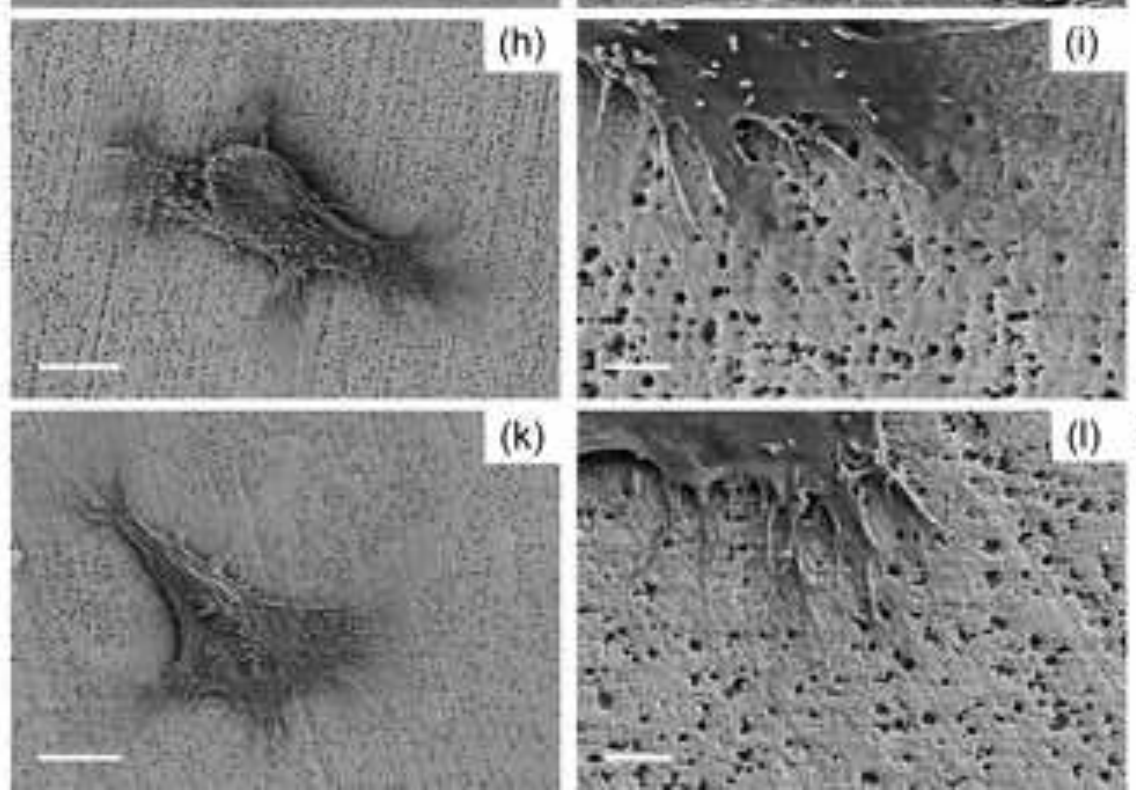

Column 3
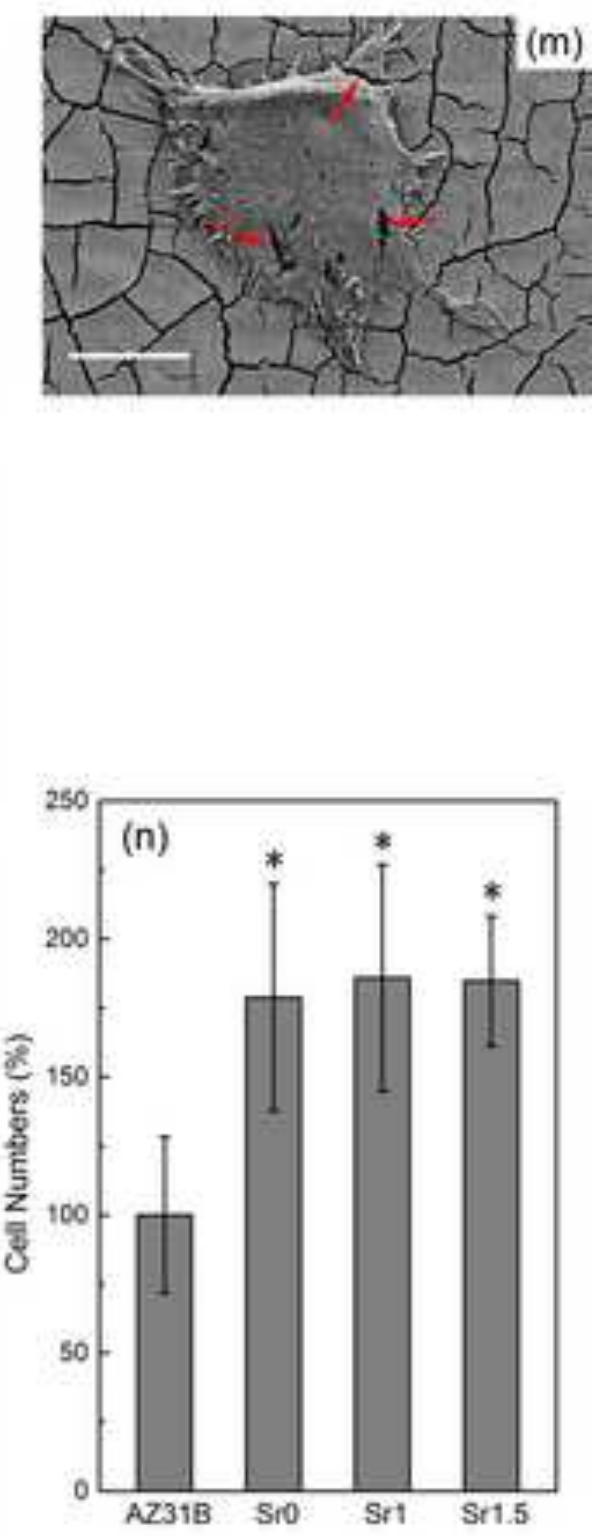

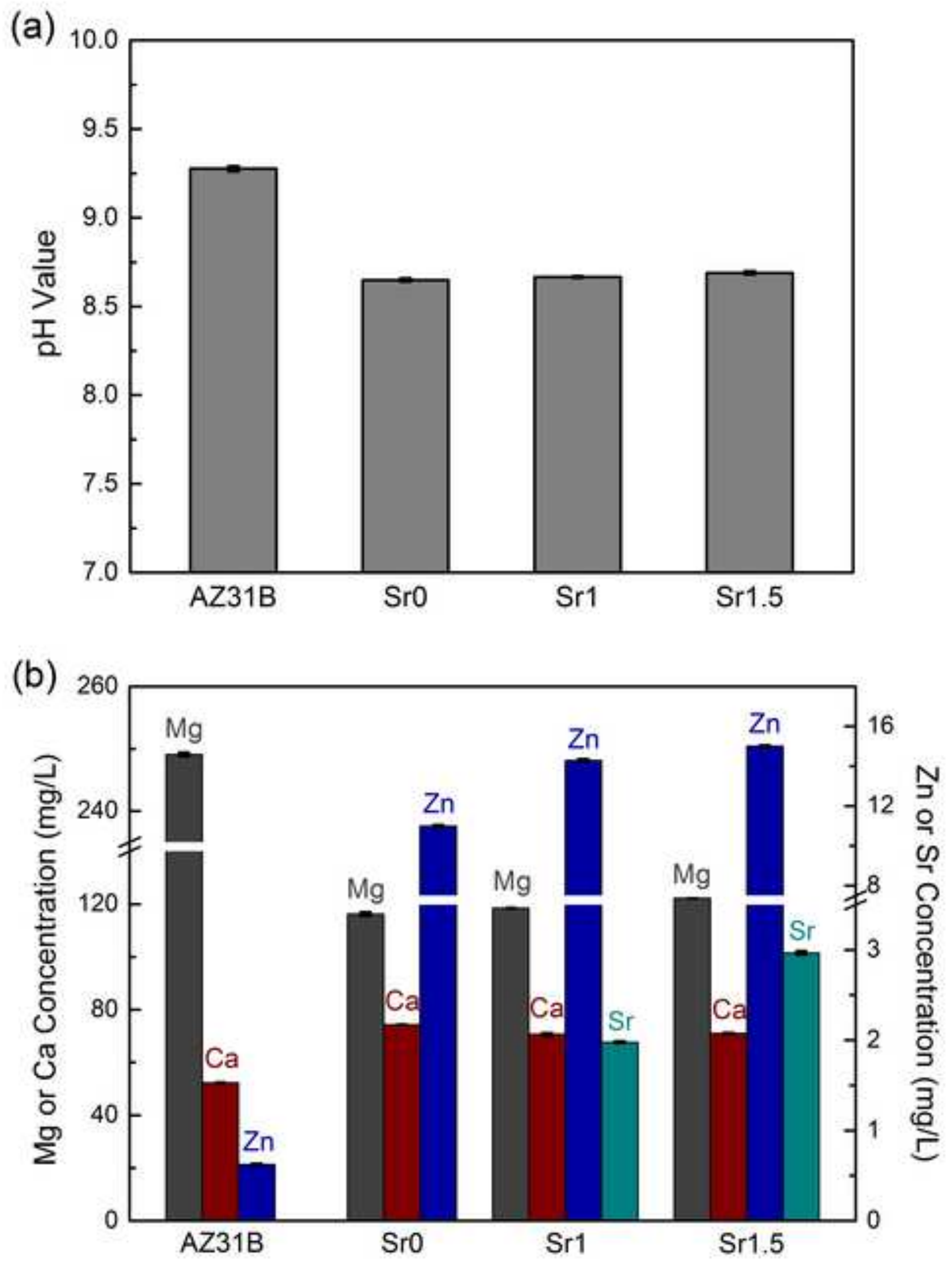

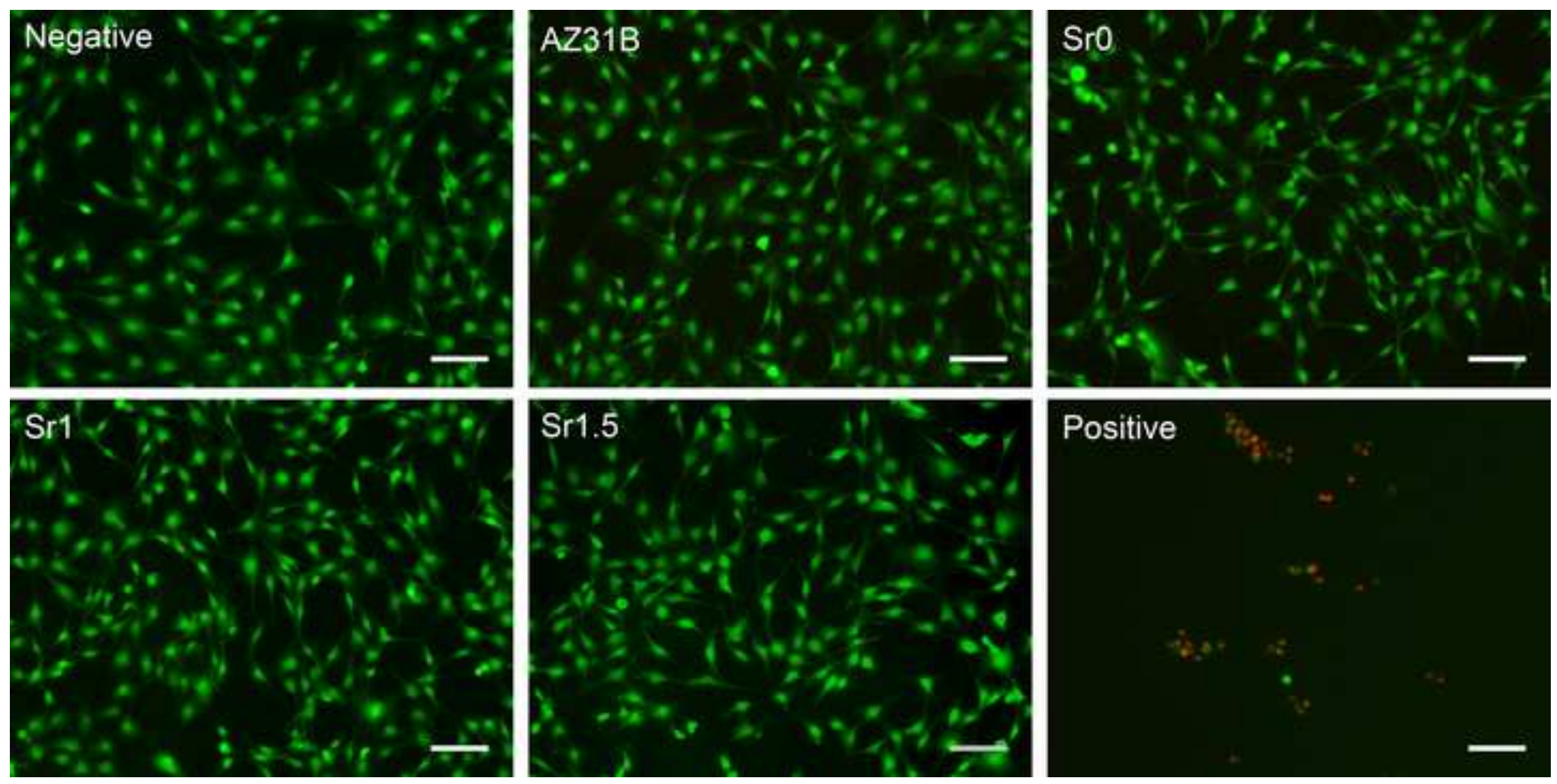

Positive

\%o

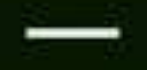




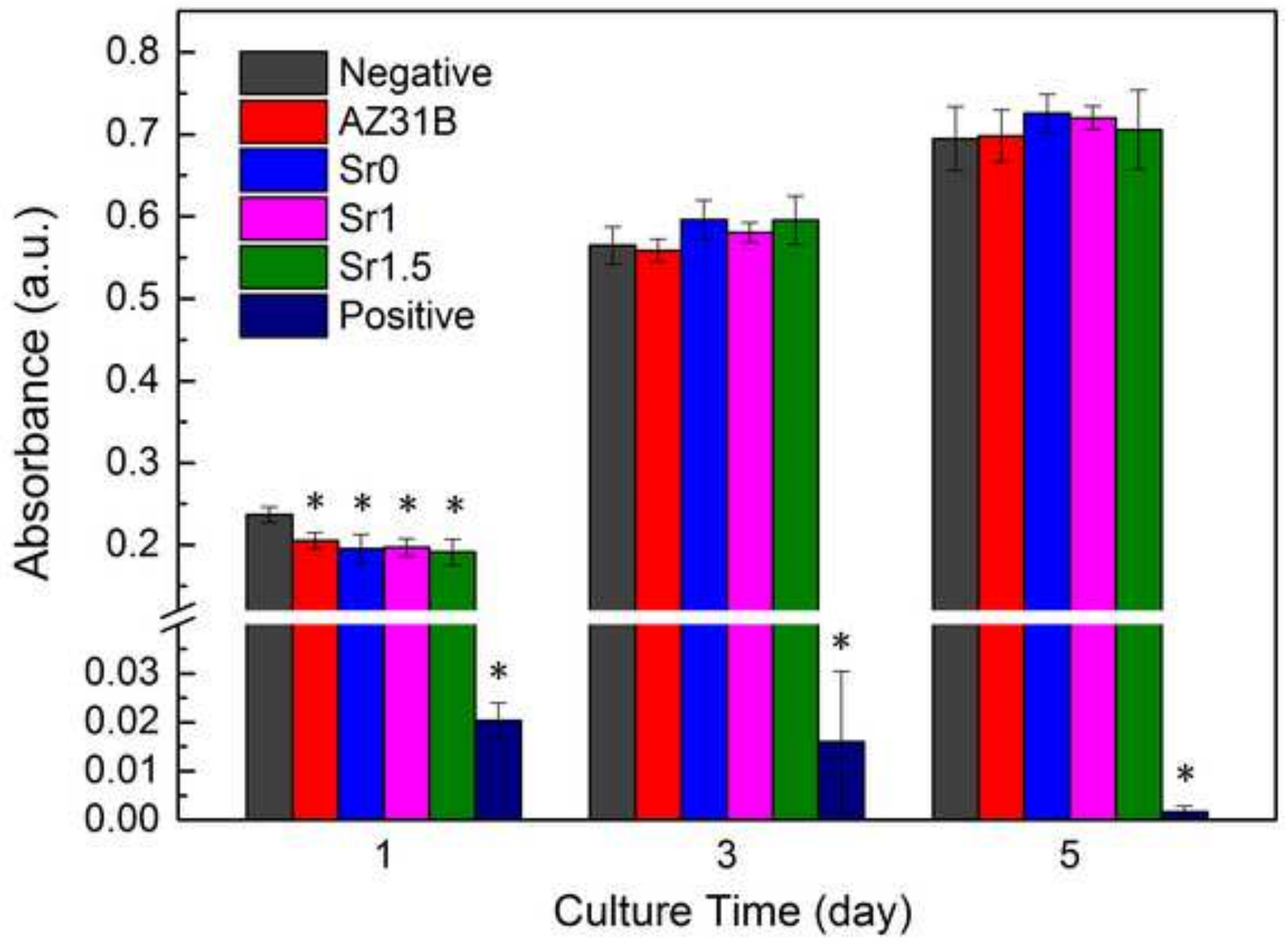




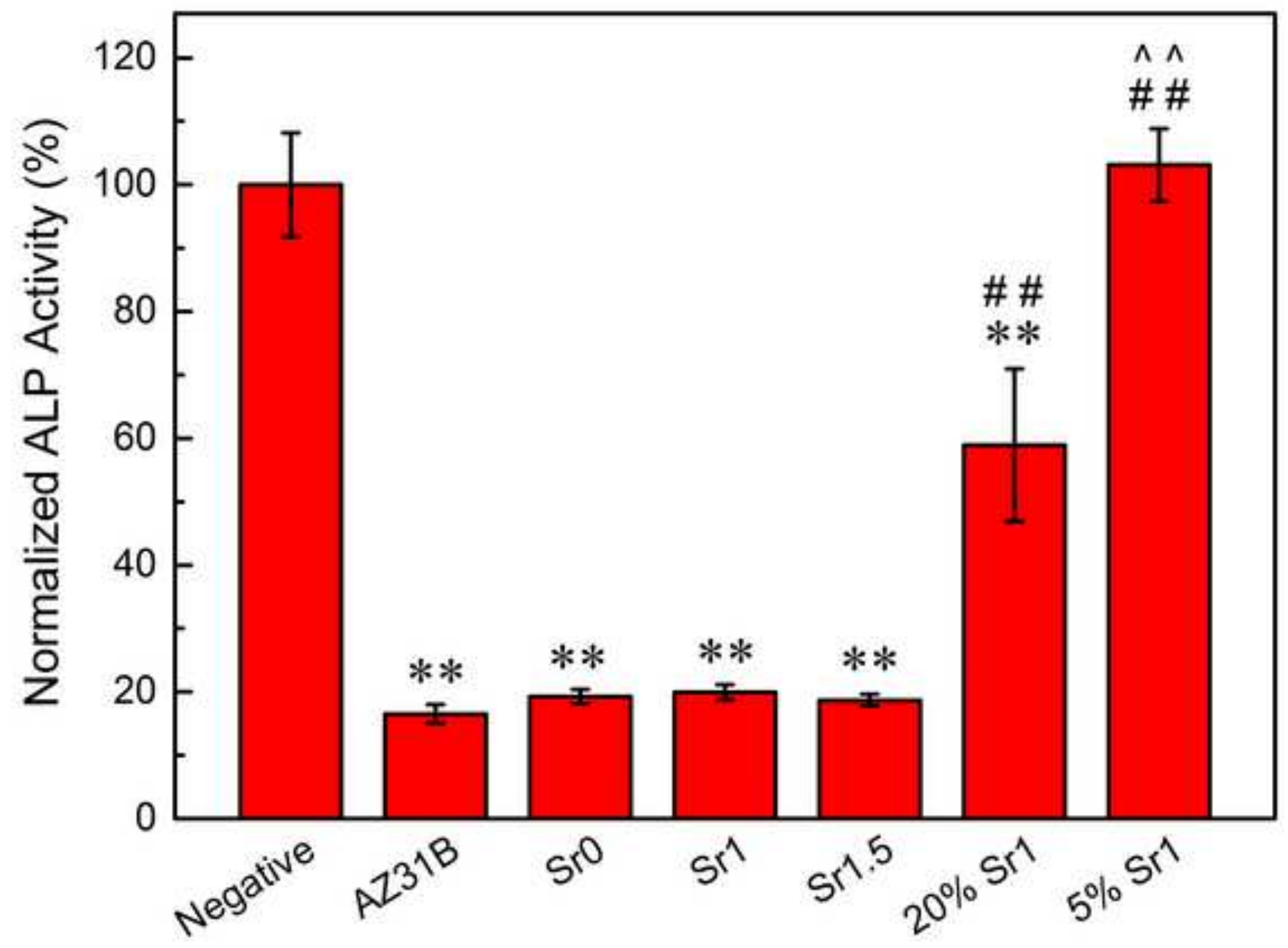


(a)

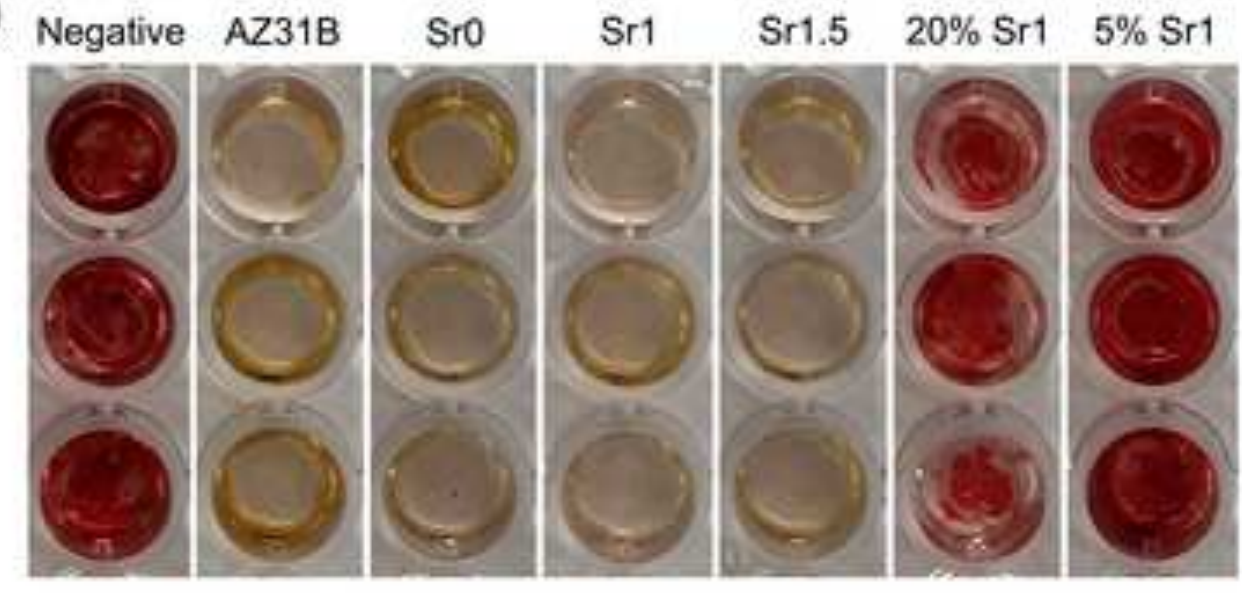

(b)

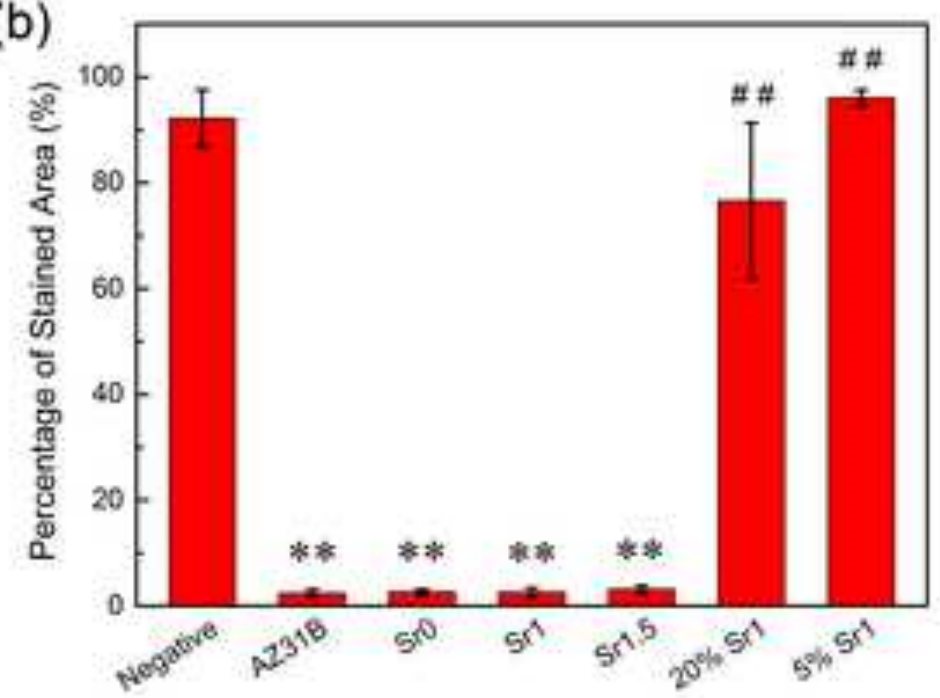




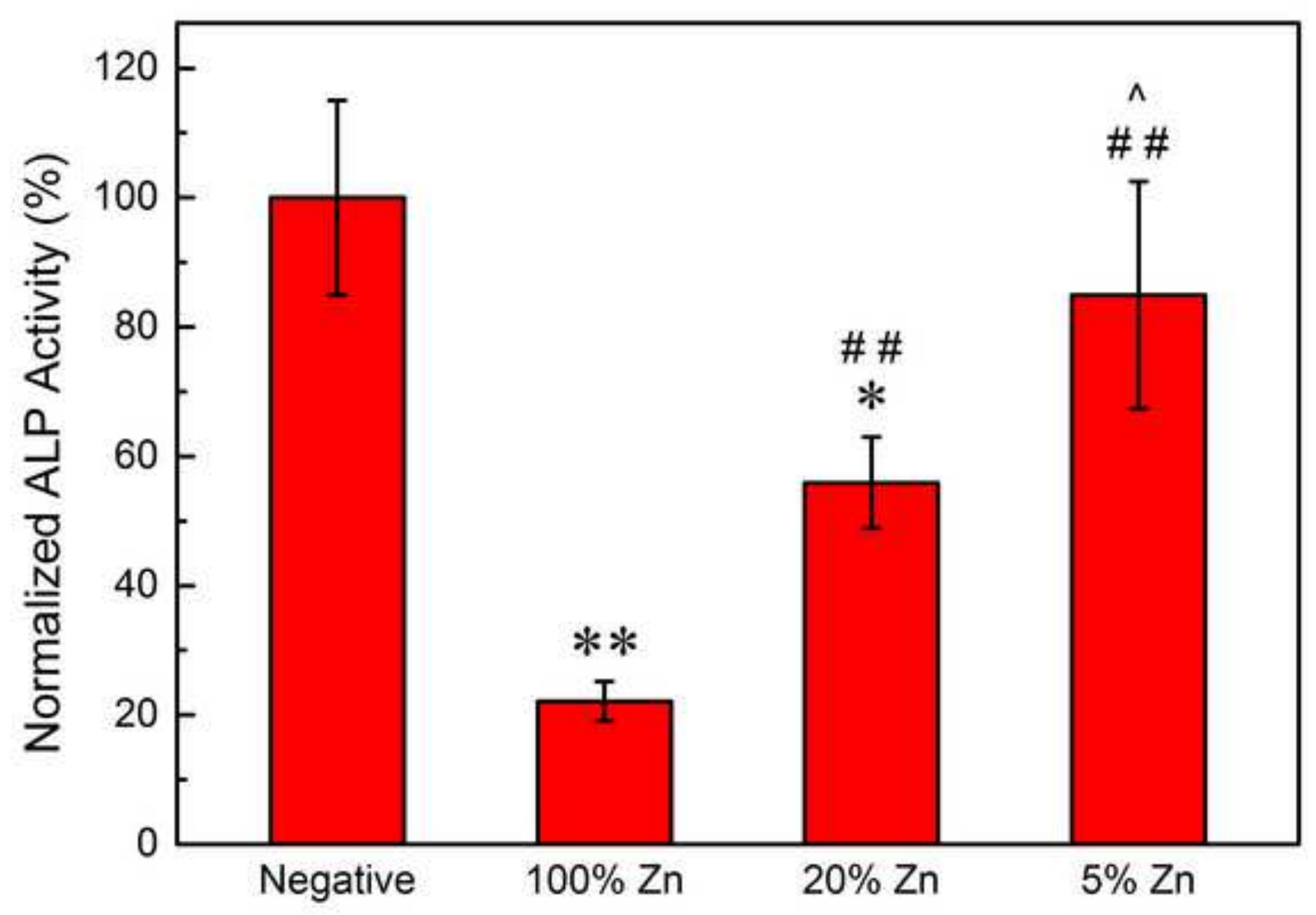


(a) Negative $\quad 100 \% \mathrm{Zn} \quad 20 \% \mathrm{Zn} \quad 5 \% \mathrm{Zn}$

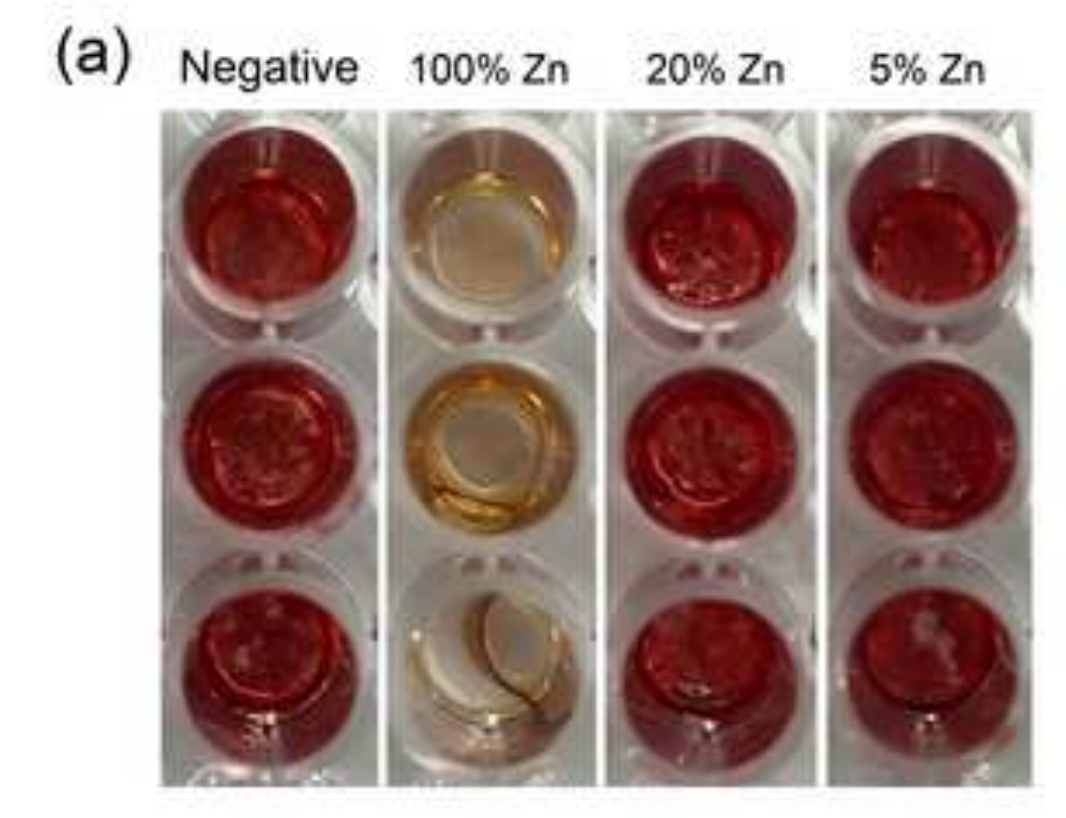

(b)

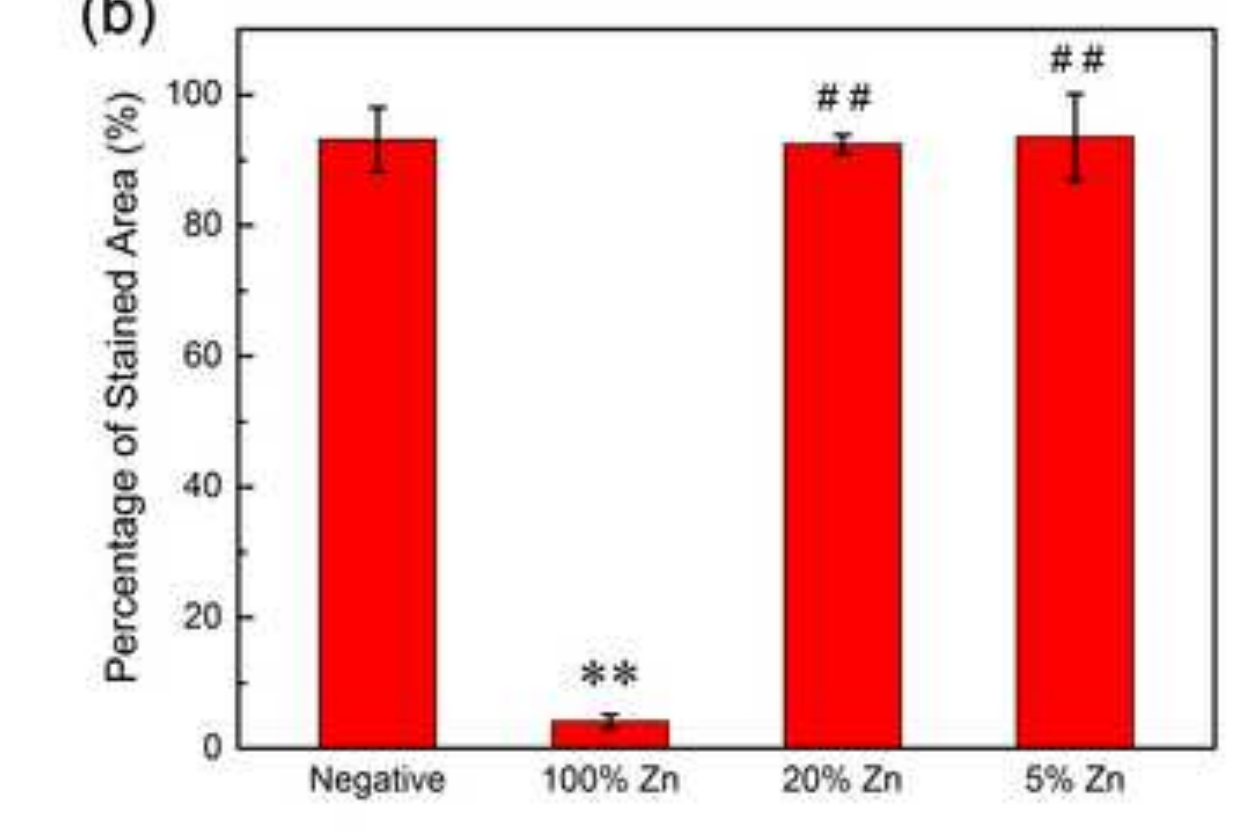


Table 1. Surface roughness $\left(R_{\mathrm{a}}\right)$, contact angle and surface free energy (SFE) of AZ31B and Mg-Zn-Ca-Sr BMGs.

\begin{tabular}{|c|c|c|c|c|c|c|}
\hline \multirow{2}{*}{ Alloys } & \multirow{2}{*}{$R_{\mathrm{a}}(\mu \mathrm{m})$} & \multicolumn{2}{|c|}{ Contact angle $\left({ }^{\mathrm{o}}\right)$} & \multicolumn{3}{|c|}{ Surface free energy $\left(\mathrm{mN} / \mathrm{m}^{2}\right)$} \\
\hline & & DI water & DII & $\gamma_{\mathrm{s}}^{\mathrm{d}}$ & $\gamma_{\mathrm{s}}^{\mathrm{p}}$ & $\gamma_{\mathrm{s}}$ \\
\hline AZ31B & $0.840 \pm 0.053^{a}$ & $57.6 \pm 1.7$ & $39.0 \pm 1.9^{a}$ & $40.1 \pm 0.9^{a}$ & $13.6 \pm 1.1$ & $53.7 \pm 0.9^{a}$ \\
\hline $\mathrm{SrO}$ & $0.746 \pm 0.080^{\mathrm{a}}$ & $54.4 \pm 1.6$ & $41.1 \pm 1.6^{\mathrm{a}}$ & $39.1 \pm 0.8^{\mathrm{a}}$ & $15.8 \pm 0.7$ & $54.9 \pm 1.3^{\mathrm{a}}$ \\
\hline Sr1 & $0.748 \pm 0.081^{\mathrm{a}}$ & $46.2 \pm 2.3^{\mathrm{a}}$ & $38.5 \pm 0.5^{\mathrm{a}}$ & $40.4 \pm 0.2^{\mathrm{a}}$ & $20.0 \pm 1.3^{\mathrm{a}}$ & $60.4 \pm 1.4$ \\
\hline $\operatorname{Sr} 1.5$ & $0.760 \pm 0.068^{\mathrm{a}}$ & $43.8 \pm 2.7^{\mathrm{a}}$ & $34.1 \pm 0.8$ & $42.4 \pm 0.4$ & $20.4 \pm 1.6^{\mathrm{a}}$ & $62.9 \pm 1.4$ \\
\hline
\end{tabular}

Results marked with the same superscript letter are not significantly different.

$\gamma_{\mathrm{s}}^{\mathrm{d}}$, dispersive part of SFE; $\gamma_{\mathrm{s}}^{\mathrm{p}}$, polar part of SFE; $\gamma_{\mathrm{s}}$, SFE. 
Table 2. Parameters of representative biodegradable Mg-, Ca- and Sr-based BMGs: $t_{\mathrm{c}}$ denotes critical thickness for glass formation, $\rho$ denotes density, $\sigma_{\mathrm{f}}$ denotes fracture strength, $\sigma_{\mathrm{f}} / \rho$ denotes specific strength, $E$ denotes Young's modulus, $R_{\text {corr }}$ denotes corrosion rate.

\begin{tabular}{|c|c|c|c|c|c|c|c|}
\hline Materials & $t_{\mathrm{c}}(\mathrm{mm})$ & $\rho\left(\mathrm{g} / \mathrm{cm}^{3}\right)$ & $\sigma_{\mathrm{f}}(\mathrm{MPa})$ & $\sigma_{\mathrm{f}} / \rho(\mathrm{Nm} / \mathrm{g})$ & $E(\mathrm{GPa})$ & $R_{\text {corr }}(\mathrm{mm} /$ year $)$ & Refs. \\
\hline Cortical bone & - & $1.8-2.1$ & $130-180$ & $70-90$ & $3-20$ & - & 6 \\
\hline Crystalline Mg alloys & - & $1.7-2.1$ & $80-300$ & $50-140$ & $40-55$ & 0.25-4.5 (Hank's) & 8 \\
\hline \multicolumn{8}{|l|}{ Biodegradable BMGs } \\
\hline $\mathrm{Mg}_{70} \mathrm{Zn}_{25} \mathrm{Ca}_{5}$ & $3^{a}$ & - & 566 & - & - & $0.41(\mathrm{SBF})$ & 18 \\
\hline $\mathrm{Mg}_{66} \mathrm{Zn}_{30} \mathrm{Ca}_{4}$ & $4^{a}$ & 2.94 & 787 & 268 & 48.8 & $0.23(\mathrm{SBF}), 0.32(\mathrm{PBS})$ & 18,20 \\
\hline $\mathrm{Mg}_{66} \mathrm{Zn}_{30} \mathrm{Ca}_{3} \mathrm{Sr}_{1}$ & $6^{\mathrm{a}}$ & 2.96 & 848 & 286 & 49.1 & 0.15 (PBS) & 20 \\
\hline $\mathrm{Mg}_{66} \mathrm{Zn}_{30} \mathrm{Ca}_{2.5} \mathrm{Sr}_{1.5}$ & $4^{a}$ & 2.98 & 841 & 282 & 49.4 & 0.24 (PBS) & 20 \\
\hline $\mathrm{Ca}_{65} \mathrm{Mg}_{15} \mathrm{Zn}_{20}$ & $15^{\mathrm{a}}$ & 2.14 & 354 & 165 & 19.0 & 1840 (Hank’s) & 44 \\
\hline $\mathrm{Ca}_{20} \mathrm{Mg}_{20} \mathrm{Zn}_{20} \mathrm{Sr}_{20} \mathrm{Yb}_{20}$ & $2^{b}$ & 3.60 & 371 & 103 & 19.4 & 0.7 (Hank’s) & 45 \\
\hline $\mathrm{Ca}_{32} \mathrm{Zn}_{38} \mathrm{Mg}_{12} \mathrm{Yb}_{18}$ & $2^{a}$ & 4.19 & 613 & 146 & 37.0 & 0.25 (Hank's) & 46 \\
\hline $\mathrm{Sr}_{40} \mathrm{Mg}_{20} \mathrm{Zn}_{15} \mathrm{Yb}_{20} \mathrm{Cu}_{5}$ & $2^{b}$ & 3.95 & 408 & 103 & 20.6 & $0.83^{\mathrm{c}}$ (Hank’s) & 47 \\
\hline
\end{tabular}

${ }^{a}$ : the diameter of rod sample; ${ }^{b}:$ the thickness of plate sample; ${ }^{c}:$ the data is calculated from the corrosion current density in the ref. 47. The data of $R_{\text {corr }}$ are obtained in the solution noted in parentheses. 